\title{
Conventional and electrical EOR review: the development trend of ultrasonic application in EOR
}

\author{
Siti Habibah Shafiai ${ }^{1} \cdot$ Adel Gohari $^{1}$ (D)
}

Received: 4 September 2019 / Accepted: 8 June 2020 / Published online: 19 June 2020

(c) The Author(s) 2020

\begin{abstract}
A small portion of oil can be extracted during primary and secondary stages of oil production, and significant quantities of oil remain in reservoirs. Enhanced oil recovery methods are used to extract the trapped oil with high viscosity in reservoirs and improve the efficiency of the production wells. Ultrasonic-based enhanced oil recovery method has become of considerable interest to researchers in recent years. This paper mainly presents the in-depth literature review of ultrasonic wave to investigate its application development trend in enhanced oil recovery. Besides, it also presents an overview of conventional enhanced oil recovery techniques such as chemical, gas, and thermal methods and nonconventional techniques such as electromagnetic and microwave heating. The results exhibit an increasing implementation of the ultrasonic waves for oil recovery since it is an inexpensive and ecologically sound method, can be applied in any type of reservoir, protects the well against damage, prevents heat loss, and enables stimulation freely.
\end{abstract}

Keywords Enhanced oil recovery $\cdot$ Conventional methods $\cdot$ Ultrasonic $\cdot$ Electromagnetic $\cdot$ Microwave heating

\section{Introduction}

Crude oil is a complex combination of different hydrocarbons such as carbon, hydrogen, sulfur, nitrogen, oxygen, metals, and salts. Hydrocarbons are the simplest organic compounds that include chemical and physical properties. The smaller hydrocarbon molecules (such as methane, propane, and butane) are found in natural gas. The larger hydrocarbons such as hexane and octane make up petroleum products. Marine organisms and macroscopic animals in plant died and settled in the bottom of the ocean approximately 2 billion years ago. Beneath the sediment in the ocean, and without oxygen, these fossils changed to a substance called kerogen. Then, kerogen slowly changes into oil or gas due to existing heat and pressure. Generally, the complete process takes at least a million years forming two main types of crude oil which are light and heavy oil. Light crude oil, which can be extracted easily, has low viscosity, low density, and high American Petroleum Institute (API)

Adel Gohari

adel.gohari@gmail.com

1 Faculty of Civil and Environmental Engineering, Universiti Teknologi PETRONAS, 32610 Bandar Seri Iskandar, Perak Darul Ridzuan, Malaysia gravity. However, heavy crude oil has a viscosity ranging from $50 \mathrm{mPa}$ s up to about $50,000 \mathrm{mPa}$ s that has limited mobility under reservoir temperature and pressure and does not flow easily (Mai et al. 2009). The global in-place resources of heavy oil are about 991.18 billion tonnes in which 126.74 billion tonnes of that is recoverable (Liu et al. 2019). The average oil recovery rates in a worldwide scale and in the USA are 30\% and 39\%, respectively (Yernazarova et al. 2016).

Oil production is broken down into primary, secondary, and tertiary phases. The primary stage is the process of oil recovery based on the natural pressure or energy of the reservoir. At first, the pressure of the reservoir is noticeably higher than that of bottomhole inside the wellbore. Then, due to this pressure difference, the oil flows into the well and up to surface. Subsequently, the pressure of the reservoir decreases due to the sustained process of recovery. Thus, to avoid the effect of reservoir pressure reduction, artificial lift devices such as pump jacks are used to maintain the production and raise the oil to the surface (Andrei et al. 2010). The primary stage continues until either the available pressure in the reservoir is significantly low or the existence of the amount of water or gas in the recovery stream is very high. The average rate of oil extraction in the primary stage is between 5 and $20 \%$ of the original oil in place (OOIP) 
(Verma 2015). Influential parameters in oil extraction in the primary stage are the mechanism of drive and properties of oil and rock.

The secondary stage of oil recovery extends the field's productive life by increasing the pressure inside the reservoirs or by oil displacement directly into the production wells and driving oil to the surface through various methods. Adopted methods in this stage include hydrocarbon gas injection, which is a very costly method for oil companies, waterflooding, which is the most common method, carbon dioxide $\left(\mathrm{CO}_{2}\right)$ injection, chemical flooding, etc. (Green and Willhite 1998). The rate of oil extraction after employing the secondary recovery method can be increased up to $40 \%$, depending on oil properties, geological and reservoir characteristics, and well configuration (Laherrere 2001; Hite and Bondor 2004; Chierici 2012; Ayirala and Yousef 2015). The recovery efficiency of primary and secondary stages is about $33 \%$ of OOIP (Godec et al. 2011), and about $67 \%$ of oil remains trapped in the reservoir (Bahadori 2018). The oil recovery rate in the primary and secondary phases is low mainly due to interfacial tension between oil and water (capillary forces), high mobility ratio, and the heterogeneities in the reservoir rock.

The tertiary recovery or enhanced oil recovery (EOR), which is usually enforceable after secondary recovery stage, is a technique used for displacement of the remaining oil trapped in the reservoir by applying injection of materials not normally present in the reservoir (Archer and Wall 2012). In other words, EOR is the technique or process where the physicochemical (physical and chemical) properties of the rock are changed to improve the efficiency of hydrocarbon production. The most significant aims of the EOR techniques are to reduce the interfacial tension between oil and water, reduce capillary pressure, and decrease of the mobility ratio between oil and water by increasing the viscosity of water (Littmann 1997; Williams 2003; Gharabi 2005; Zhu et al. 2005). Thomas (2008) pointed out that the type of reservoir has a remarkable influence on the EOR target, as shown in Fig. 1. In light oil reservoirs, application of the primary and secondary stages enables extraction of $55 \%$ of oil in place (OIP), and remaining oil (45\%) can be recovered by using EOR methods. However, EOR methods are responsible for a very big portion of oil extraction in heavy oil reservoirs and tar sands since these types of reservoirs have a very poor response to the primary and secondary stages. The EOR techniques can be employed in circumstances such as when the well is damaged because of overusage of the drilling mud or it is damaged by salt and sediments, there is no increase in recovery rate while water and acid are injected into the well, there is low production rate while the well's production is potentially high, and heavy oil and paraffin are produced by the wells (Speight 2013).

Our contribution attempts to provide an overview of the conventional and nonconventional EOR methods, more specifically the development trend of the ultrasonic stimulation technique in oil recovery improvement. The section after Introduction is discussing conventional methods of EOR. In the next section, the EOR screening is discussed. The next section discusses electrical-based enhanced oil recovery (EEOR) which includes electromagnetic heating and ultrasonic stimulation. The next section presents conducted researches related to the implications of the ultrasonic waves in EOR. The last section contains our conclusions.

\section{Conventional methods of EOR}

Conventional EOR methods include chemical (CEOR), gas injections, thermal recovery, microbial (MEOR), low-salinity waterflood, and foam-EOR, among others. Each EOR method is constituted of different techniques which is shown in Table 1 (Kong and Ohadi 2010; Alvarado and Manrique 2010; Ayatollahi and Zerafat 2012; Viebahn et al. 2015; She et al. 2019).

CEOR methods include traditional methods such as polymer flooding, surfactant, and alkaline flooding, combined traditional methods such as surfactant-polymer (SP), alkaline-surfactant-polymer (ASP), etc., and foam processes.
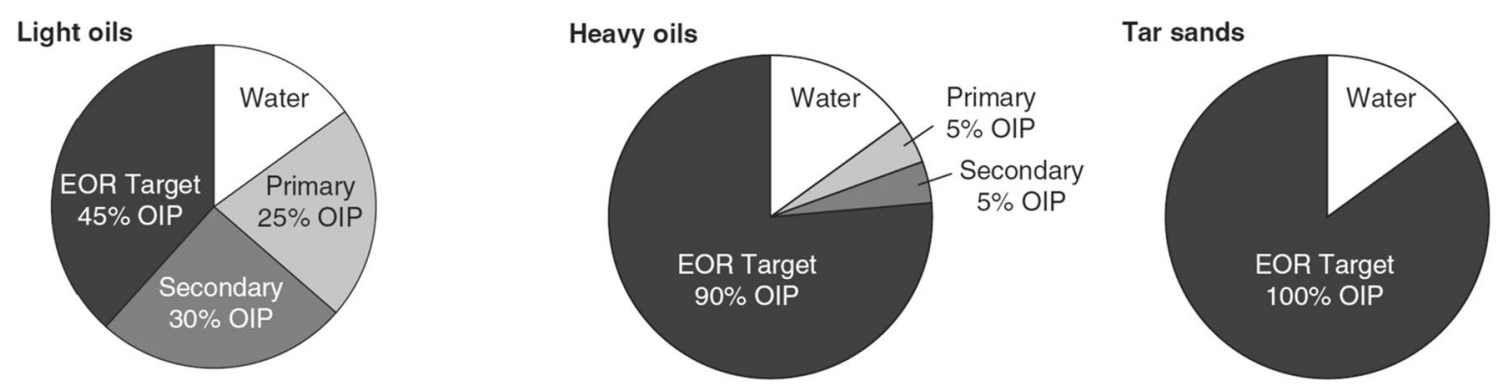

(Assuming Soi $=85 \% \mathrm{PV}$ and $\mathrm{Sw}=15 \% \mathrm{PV}$ )

Fig. 1 EOR target for different oil reservoir types (Thomas 2008)

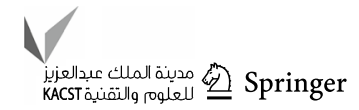


Table 1 Different methods of conventional EOR

\begin{tabular}{|c|c|c|c|}
\hline Chemical methods & Microbial & Gas methods & Thermal methods \\
\hline Alkaline flooding & Microbial flooding recovery (MFR) & Hydrocarbon gas injection & Steam flooding \\
\hline Polymer flooding & Cycle microbial recovery (CMR) & $\mathrm{N}_{2}$ injection & In situ combustion \\
\hline Surfactant flooding & $\begin{array}{l}\text { Microbial selective plugging recovery } \\
\text { (MSPR) }\end{array}$ & $\mathrm{CO}_{2}$ injection & Cyclic steam stimulation (CSS) \\
\hline Micellar flooding & Others & Air injection & $\begin{array}{l}\text { Steam-assisted gravity drainage } \\
\text { (SAGD) }\end{array}$ \\
\hline $\begin{array}{l}\text { Alkaline-surfactant-polymer (ASP) } \\
\text { flooding }\end{array}$ & & $\begin{array}{l}\text { Water-alternating-gas } \\
\text { (WAG) injection }\end{array}$ & Electrical heating \\
\hline \multicolumn{4}{|l|}{ Foaming agents, acids, and solvents } \\
\hline Low-salinity water flooding (LSW) & & & \\
\hline
\end{tabular}

CEOR methods are applicable to light oil reservoirs (Alvarado and Manrique 2010), attempting to decrease interfacial tension (IFT), brine viscosity increment for mobility control, and sweep efficiency enhancement of the injected fluid (Shah 2012; Azam et al. 2013). Using these methods enhances either microscopic (pore scale) or macroscopic (volumetric sweep) displacement efficiency or both. For instance, polymer increases the macroscopic displacement efficiency, while surfactants improve the microscopic displacement efficiency. Polymer is used to viscosities the water by improving the mobility ratio and fluid flow patterns of a displacement process (Fanchi 2018). Surfactant, which contains one hydrocarbon chain (lipophilic) and a polar head (hydrophilic) (Hakiki et al. 2015b), reduces the IFT between oil and water and alters wettability. Alkali, which includes sodium carbonate and sodium tetraborate (Borax) as respective conventional and novel alkali, generates in situ soaps by reacting with organic-acid components present in the crude oil. Additionally, it reduces the surfactant adsorption by modifying rock surface-charge characteristic (Ayirala and Yousef 2015). However, these traditional chemical methods have disadvantages. For instance, the problem of using polymer is the loss of viscosity in the presence of reservoir brines and with temperature increase, and utilizing surfactant and alkali has efficiency loss limitation while flowing in porous media (Gbadamosi et al. 2019). Therefore, implementing combinational modes has attracted more attention, and their applications resulted in higher oil recovery rate. Lately, using foams combined with surfactants and polymers shows promising results in oil recovery improvement since it causes more stability and better control of mobility. LSW is one of the methods that causes oil recovery enhancement by injection of reduced water salinity. Although the first report of LSW application in EOR was published by Bernard (1967), it gained considerable attention from 2005 onward mainly because of its low facility investment and subsequently low cost (Katende and Sagala 2019; Marhaendrajana et al. 2018; Sheng 2014), and environmentally friendly manner (Marhaendrajana et al. 2018; Sheng 2014).
Several LSW-based recovery mechanisms have been introduced by various researchers in the past couple of decades: for instance, a mechanism based on mixed wet clay release (Yu et al. 2019), PH effect (Austad et al. 2010), multicomponent ionic exchange (Lager et al. 2008), wettability alteration (Zhang et al. 2007), and osmotic pressure (Pollen and Berg 2018). However, there is a lack of consistent LSW mechanism which can be due to different test approaches, complexity of the minerals, crude oils, and aqueous-phase compositions and the interactions among all these phases (Chavan et al. 2019). More recent studies regarding different methods of CEOR can be found at Hakiki et al. (2015a) for polymer, Hakiki et al. (2015b) and Dang et al. (2018) for ASP, Haghighi and Firozjaii (2019) and Azam et al. (2013) for surfactant, Rai et al. (2015) for surfactant-polymer, Dang et al. (2014) and Goswami et al. (2018) for micellar flooding, Nasr et al. (2020), Syed et al. (2019), and Samin et al. (2017) for foam-EOR, Al-Sarihi et al. (2018), Almansour et al. (2017), Al-Saedi et al. (2019), Chen et al. (2006), Zekri et al. (2019), Fredriksen et al. (2017), and Alfazazi et al. (2019) for LSW.

MEOR is a biological technology that uses the injection of nutrients and microbial products such as gases (H2, N2, $\mathrm{CH} 4, \mathrm{CO} 2$ ), organic acids, solvents, biosurfactants, biopolymers, and biomass (microbial cells) to decrease water production in reservoirs, improve the oil recovery, or both (Putra and Hakiki 2019; Fanchi 2018). The implementation of these methods enhances the macroscopic displacement efficiency by decreasing oil viscosity and increasing reservoir pressure. Safdel et al. (2017) categorized the processes of MEOR into microbial flooding recovery (MFR) which is the most effective method (Ismail et al. (2017); Al-Sayegh et al. (2017)), cycle microbial recovery (CMR), microbial selective plugging recovery (MSPR), and others. Typically, in microbial flooding, microbes and nutrients are injected into reservoirs from the injection wells where microorganisms and their metabolites move along with water to assist the transport of oil toward and out of the production wells (Ke et al. 2018a). Compared with other EOR techniques,

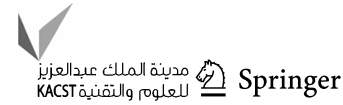


MFR includes a variety of advantages, such as lower energy consumption and the reduced loss caused by degradation by some of the endogenous microorganisms (Zahid and Khan 2007), more environmental friendliness (She et al. 2019; Ke et al. 2018b; Patel et al. 2015), and inexpensiveness (She et al. 2019; He et al. 2018a; Zahid and Khan 2007). He et al. (2018a) reported the cost per incremental oil for MEOR, gas flooding, steam flooding, combustion in situ, and chemical flooding in ranges such as from 1 to 4 , from 2 to 8 , from 3 to 6, from 5 to 10 , and from 8 to $12 \mathrm{USD} / \mathrm{bbl}$, respectively. In another study, Cui, (2017) estimated the cost of MEOR as 10 USD/bbl, while for chemical flooding, thermal production, and $\mathrm{CO} 2$ flooding, it was calculated as 21,28 , and $31 \mathrm{USD} /$ $\mathrm{bbl}$, respectively. For MEOR application, the reader referred to researches Câmara et al. (2019), Landa-Marbán et al. (2017), Gao (2018), and Haq et al. (2019), among others.

Gas injection methods involve the injection of gasses such as $\mathrm{CO}_{2}$, nitrogen $\left(\mathrm{N}_{2}\right)$, hydrocarbon, and alternating hydrocarbon gas (WAG) into the reservoir in different schemes such as continuous, water alternating, and cyclic. The key mechanisms of these methods include maintenance of reservoir pressure, swelling of oil, and declining of oil viscosity (Sheng 2015). According to Jia et al. (2019), gas accessibility and economic consideration are main factors influencing the selection of gas type to be used in the field, and permeability level is the factor for scheme selection (continues schemes in cases with permeability larger than $0.01 \mathrm{mD}$, while cyclic scheme in ultralow permeability shale reservoirs). There are two types of gas injection which are miscible and immiscible. In the case of miscible gas injection, the injected gas is dissolved within the oil inside the reservoir and underlying oil starts flowing toward the production well. In this method, the gas is injected at or above minimum miscibility pressure (MMP). In immiscible gas injection, the injected gas is absorbed inside the oil and water and it will cause movement and mixture of oil blobs and start flowing toward the production well. In other words, the immiscible gas flooding causes the reservoir pressure enhancement, which in turn increases the macroscopic displacement efficiency, and subsequently, improves the oil recovery. In this method, the injection of gas needs to be below MMP. So, in this condition, the $\mathrm{CO}_{2}$ and oil will not form a single phase. However, $\mathrm{CO}_{2}$ will dissolve in the oil enabling oil swelling improvement and reducing oil viscosity (El-Hoshoudy and Desouky 2018). Additionally, gas injection in low pressure enables to keep the pressure of the reservoir in the stable condition causing prevention of production cutoff, and subsequently, facilitate more oil recovery (Al-Anazi 2007). According to Kulkarni (2003), the $\mathrm{CO}_{2}$-based EOR is the second-most approach being implemented in heavy oil fields around the world after thermal approaches. However, its economic efficiency must be well considered before deployed in oil fields. In this regard, the initial capital cost of the project (wells drilling, $\mathrm{CO}_{2}$ recycling plant, corrosion-resistant field production infrastructure, $\mathrm{CO}_{2}$ pipeline network, and price of $\mathrm{CO}_{2}$ ), the condition of the reservoirs, and the price of oil can be taken into account as the most influential parameters (Perera et al. 2016). The $\mathrm{CO}_{2}$-assisted EOR is being used in 114 projects in the USA (Meribout 2018). The wide implementation of this method in the USA is because of available natural sources of $\mathrm{CO}_{2}$ and the existing $\mathrm{CO}_{2}$ pipeline network (Manrique et al. 2007). The $\mathrm{CO}_{2}$ injection method is beneficial due to its large storage capacity (Perera et al. 2016) and decreasing atmospheric gas emissions through CO2 storage (Bachu and Adams 2003), while its drawback is it alters the volumetric sweep efficiency (Meribout 2018). The $\mathrm{CO}_{2}$ gas is injected either continuously or in alternate slugs with water, known as WAG flooding. Adoption of WAG process results in better recovery from improved mobility control in contrast to continuous gas injection (Ayirala and Yousef 2015). In fact, the high ratio of mobility is not beneficial to oil recovery since it causes early gas breakthrough and availability of a small amount of recycled gas in the high-permeability zone (Jia et al. 2019). Saneifar et al. (2017) pointed out that one of the problems of WAG is some degree of loss of injectivity in most floods, more specifically in reservoirs with permeability less than of 10 $\mathrm{mD}$. Adjusting WAG ratios and drilling new wells assist in decreasing this loss as they provide different configurations of EOR site-specific $\mathrm{CO}_{2}$ injection (Núñez-López et al. 2019). The hydrocarbon and nitrogen injections are broadly implemented for cases such as gas cycling, maintenance of reservoir pressure, and gas lift in oil fields. They are noncorrosive and cheaper than $\mathrm{CO}_{2}$-based EOR (Stevens et al. 1999). The most recent literature regarding gas injection utilization can be found in researches done by Buenaventura et al. (2014), Gbadamosi et al. (2018), Lashgari et al. (2019), Belazreg et al. (2019), Wan et al. (2015), and Tovar et al. (2018).

Thermal methods are the main EOR process for heavy oil extraction ( $\mathrm{Li}$ et al. 2017). Thermal EOR is typically implemented on shallow reservoirs with large fields. These methods enhance both macroscopic and microscopic displacement efficiencies by the reduction in viscous forces and interfacial tension, respectively. Conventional thermal-based EOR techniques include in situ combustion and steam-assisted methods such as CSS, SF, and SAGD. In situ combustion method is the injection of air or oxygen in order to generate heat between 450 and $600{ }^{\circ} \mathrm{C}$ within the reservoir by burning about $10 \%$ of the OIP. The generated heat causes a reduction in the surface tension, reduces the oil viscosity in an area near the combustion zone, and increases the oil permeability. This method can be applied on wide range of reservoir and crude-oil types (Zhao et al. 2015). The main problems of this method can be considered as severe corrosion, toxic gas production, and gravity override (Thomas 
2008). In CSS (also known as Huff n' Puff) method, steam is injected into the reservoir for about a month, and then the well is shut in for few days for heat distribution. The rate of oil production at the beginning is high due to a variety of factors such as high initial oil saturation, high increased reservoir pressure, and lowered oil viscosity. The production of the well will continue for several months until the oil recovery rate decreases into uneconomic rate when the cycle is necessary to be repeated. The recovery factor of this method is low, and it is between 10 and $40 \%$ OIP. SF is a pattern-driven method, and its performance depends on geology and pattern size enormously. Typical recovery factors are between 50 and 60\% OIP (Thomas 2008). In SAGD technique, the injection well (upper horizontal well) is used for continuous low-pressure steam injection to the formation which in turn causes the creation of steam chamber (steamsaturated zone). The gravity force causes gradual expansion of the steam chamber vertically. The steam chamber transfers the heat of the injected steam into the formation and causes oil movement and drainage (due to gravity force) toward the production well (lower horizontal well). According to Speight (2011), using the SAGD method improves the steam-oil ratio and enables improvement in oil recovery by $60 \%$ to $70 \%$. Adoption of conventional thermal-based EOR results in easy extraction of the oil by adding heat to the reservoir which causes oil viscosity reduction and lighter components vaporization. However, these methods are not suitable for heavy oil reservoirs or deep wells because of their excessive heat loss (Eskandari et al. 2015). In addition, application of these methods in long-term recovery of crude oil usually leads to formation damages due to deposition of paraffin near the wellbore, reduction in the formation permeability, incursion of outside liquids and solids for various types of production operations, and consequently, reduction in the rate of oil production (Mohsin and Meribout 2015; Meribout 2018). Furthermore, thermal methods are not environmentally friendly and cause an increase in greenhouse gas production (Mukhametshina and Martynova 2013). Also, adopting thermal methods in heterogeneous reservoirs is not favorable (Sadeghi et al. 2017) since there is a possibility of occurrence of early fluid breakthrough and sweep reduction due to fractures and high permeability streaks (Saeedfar et al. 2016). Additionally, the steam-assisted methods include high implementation and operation cost (Xiaoxiong et al. 2018), less economic efficiency in thin pay zones and low-permeability formations (clark 2007), not applicable on for deep or very shallow reservoirs (Bientinesi et al. 2013), and their efficiency is highly influenced by geological properties of the reservoir (Bientinesi et al. 2013). Finally, these techniques are considered as time-consuming methods and need huge resources of water (Saeedfar et al. 2016) for heating since they usually heat a large area of the reservoir (Chakma and Jha 1992). The comprehensive information regarding thermal methods can be found at Sheng (2013), Wu and Liu (2019), Shen (2013), Banerjee and Hascakir (2018), and Ghalenavi et al. (2020).

\section{EOR screening}

The different characterization of EOR methods declares the fact that one particular technique should not be utilized for all reservoir types. Thus, the most suitable method needs to be identified for specific reservoir conditions which can be obtained through EOR screening. The goal of EOR screening is to select an optimized method among alternatives or prioritizing alternatives based on reservoir characteristics and oil properties criteria. These criteria can be grouped into rock and fluid parameters in which rock parameters include porosity, permeability, initial oil saturation, and depth, while gravity, viscosity, and temperature comprised fluid parameters (Kamari et al. (2015). Different methods are adopted for EOR screening purposes: for example, using tables and graphs (Kamari et al. 2015), artificial intelligence (AI) methods [Suleimanov et al. (2016), Eghbali et al. (2016), and Hartono et al. (2017)], and multicriteria decision analysis (MCDA) (Khojastehmehr et al. 2019). The details of the above-mentioned studies with their findings are summarized in Table 2. Beside these studies, Kang et al. (2016) comprehensively studied EOR screening criteria for onshore and offshore fields and introduced screening criteria for successful application of EOR techniques such as hydrocarbon gas miscible, $\mathrm{CO}_{2}$ miscible, and polymer processes in offshore oil fields. Another point regarding utilization of EOR method in a certain oil field is that besides technical issues (reservoir characteristics and oil properties, and operation complexity), economic factors such as investment cost (Hartono et al. 2017) and worldwide oil price are also essential to be taken into account before final decision-making process (Kamari and Mohammadi 2014).

\section{Electrical-based EOR (EEOR)}

Besides conventional EOR methods, some nonconventional methods such as electrical heating techniques are also being utilized to improve the recovery of heavy oil, which constitute $70 \%$ of total world oil reserves (Mozafari and Nasri 2017), in terms of efficiency, cost, and time (Jeong et al. 2015). EEOR methods include electromagnetic heating, ultrasonic stimulations, etc. Basically, these methods supply the electrical energy to the reservoir, which will cause an increase in oil temperature or make vibrations in the hydrocarbon molecules. This will result in a reduction in oil viscosity and increase in the oil mobilization and consequently increase in oil production. Commonly, the mechanisms of

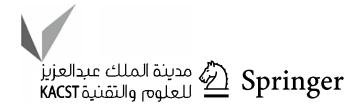


Table 2 EOR screening studies

\begin{tabular}{|c|c|c|c|c|c|c|}
\hline \multirow[t]{2}{*}{ Researcher } & \multirow{2}{*}{$\begin{array}{l}\text { Number of } \\
\text { EOR meth- } \\
\text { ods }\end{array}$} & \multirow[t]{2}{*}{ Field } & \multirow{2}{*}{$\begin{array}{l}\text { Number of } \\
\text { tested reser- } \\
\text { voirs }\end{array}$} & \multicolumn{3}{|l|}{ Reservoir } \\
\hline & & & & Location & Condition & Formation \\
\hline Kamari et al. $(2015)^{*}$ & 12 & Onshore & 1 & Iran & Naturally fractured & Carbonate \\
\hline Eghbali et al. (2016)** & 4 & Onshore & 7 & $\begin{array}{l}\text { USA } \\
\text { Venezuela } \\
\text { France }\end{array}$ & Depleted non-fractured & Sandstone \\
\hline Suleimanov et al. (2016)*** & 7 & Onshore and offshore & 11 & $\begin{array}{l}\text { Canada } \\
\text { Azerbaijan }\end{array}$ & - & - \\
\hline Hartono et al. (2017) $* * * *$ & 15 & Onshore & 9 & Indonesia & - & Sandstone \\
\hline Khojastehmehr et al. (2019)***** & 10 & Onshore and offshore & 65 & Iran & - & $\begin{array}{l}\text { Carbonate } \\
\text { and sand- } \\
\text { stone }\end{array}$ \\
\hline \multicolumn{7}{|l|}{ Remarks } \\
\hline * & \multicolumn{6}{|c|}{$\begin{array}{l}\text { In terms of technical issues, polymer, } \mathrm{CO}_{2} \text { miscible and immiscible are } \mathrm{n} \\
\text { Thermal methods and the added alkaline solvent method are not suitable } \\
\text { bonate reservoirs } \\
\text { Totally, suitability of EOR methods is as follows: } \\
\text { CEOR: in mid-viscosities, mid-depths, and mid-densities; } \\
\text { gas flooding methods: in light oils, low viscosities and deep reservoirs; } \\
\text { thermal methods: in shallow reservoirs, viscous and heavy oils }\end{array}$} \\
\hline$* *$ & \multicolumn{6}{|c|}{$\begin{array}{l}\mathrm{CO}_{2} \text { miscible injection for a low-temperature and shallow reservoir with light reservoir fluid } \\
\text { Hydrocarbon miscible injection for a very deep reservoir with a very high temperature } \\
\text { Polymer flooding for reservoir with medium depth and temperature, high viscosity oil (low API gravity) } \\
\text { Steam injection for a very shallow depth reservoir and high permeability of rock with very low API grav- } \\
\text { ity fluid } \\
\mathrm{CO}_{2} \text { miscible and } \mathrm{HC} \text { miscible for reservoir with a medium temperature, high depth, very low viscosity, } \\
\text { and light API gravity }\end{array}$} \\
\hline$* * *$ & \multicolumn{6}{|c|}{$\begin{array}{l}\text { The } \mathrm{CO}_{2} \text { flooding is the most prominent technique for Alberta's oil reservoir condition, followed by } \\
\text { hydrocarbon flooding and polymer flooding } \\
\text { Miscible } \mathrm{CO}_{2} \text { and immiscible nitrogen are most suited techniques in Guneshli (offshore Azerbaijani } \\
\text { reservoir) }\end{array}$} \\
\hline$* * * *$ & \multicolumn{6}{|c|}{$\begin{array}{l}\text { CEOR is suitable for minimum depth and temperature reservoir, and l } \\
\text { Heating-based EOR is suitable for high oil viscosity cases } \\
\text { Gas-based EOR is suited for light oil reservoir with high temperature }\end{array}$} \\
\hline$* * * * *$ & \multicolumn{6}{|c|}{$\begin{array}{l}\text { The most important criterion among screening criteria is lithology } \\
\mathrm{CO}_{2} \text { (Immiscible and miscible) is the first choice } \\
\text { In onshore reservoirs, immiscible } \mathrm{CO}_{2} \text { and hydrocarbon gas injection for onshore reservoirs and } \mathrm{CO}_{2} \\
\text { injection and steam flooding in offshore reservoirs are best methods } \\
\text { Miscible } \mathrm{N}_{2} \text { method ranked as the least important technique }\end{array}$} \\
\hline
\end{tabular}

these methods are based on heating the well (both vertical and horizontal) or formation. The former one utilizes a thermal process to heat the steam chamber or the near-wellbore well directly (Yao et al. 2019), while the latter mechanism implements the SAGD method to heat the formation by gravity drainage (Yongbin et al. 2017). Compared to the steam flooding method, the electrical heating methods are more efficient in a heterogeneous reservoir environment (Carrizales and Lake 2009), and they are better in the reservoir depth and heat loss control aspects (Acar 2007). The limitations and benefits of different EEOR techniques are mentioned in Table 3.

Electromagnetic (EM) heating is an alternative method for heavy oil recovery by heating the reservoir fluids without much loss of heat to the surroundings. In fact, EM heating refers to heating produced by the absorption of EM energy by the molecules information. The EM methods can be divided into three categories depending on the frequency of electrical current being used: inductive heating (IH), low-frequency (resistive), and high-frequency where current is alternating (Eskandari et al. 2015). The mechanisms for low-frequency and high-frequency heating are electric conduction, which results in Joule heating, and dielectric polarization, respectively (Saeedfar et al. 2016). IH is used to generate heat near wellbore in vertical wells by installing the inductive tool close to the heavy formation of the reservoir. In $\underline{\mathrm{IH}}$, a range of low- and medium-frequency electric currents can be applied which depends on the presence of energy (Hascakir et al. 2008). Low-frequency electric current may occur when low-frequency alternating current, 
Table 3 Comparisons between EEOR techniques

\begin{tabular}{|c|c|c|}
\hline EEOR method & Limitations & Benefits \\
\hline \multicolumn{3}{|c|}{ Electromagnetic (EM) heating } \\
\hline Inductive & $\begin{array}{l}\text { Providing only limited heat around the wellbore } \\
\text { (Hasanvan and Golparvar 2014) }\end{array}$ & $\begin{array}{l}\text { *More safer, advanced, and high quality of heating } \\
\text { procedure, high efficiency and faster heating (Lucía } \\
\text { et al. 2018) } \\
\text { *Applicable on various types of reservoirs with differ- } \\
\text { ent characteristics (Oliveira et al. 2009) } \\
\text { *Favorable for reservoirs which thermal methods are } \\
\text { not suitable (Rehman and Meribout 2012) }\end{array}$ \\
\hline Low frequency & $\begin{array}{l}\text { Non-uniform temperature pattern (Saeedfar et al. } \\
\text { 2016) }\end{array}$ & $\begin{array}{l}\text { Can be considered as an alternative for steam injection } \\
\text { method and suitable for reservoirs with high perme- } \\
\text { ability or fractures (Rehman and Meribout 2012) }\end{array}$ \\
\hline MW \& RF heating & $\begin{array}{l}\text { *Effective energy only able to penetrate into the very } \\
\text { near wellbore region (Hasanvand and golaparvar } \\
\text { 2014) } \\
\text { *Limited penetration depth of microwaves in conduc- } \\
\text { tive mediums (watersaturated fluid) (Troch et al. } \\
\text { 1996) }\end{array}$ & $\begin{array}{l}\text { *Propagation ability independent from transporting } \\
\text { material (Carrizales et al. 2008) } \\
\text { *Covering heat distribution over a large volume of res- } \\
\text { ervoir (Bientinesi et al. 2013; Saeedfar et al. 2016) } \\
\text { *The formation of geology is not much effective on } \\
\text { this method. Highly efficient method in the energy } \\
\text { generation-radiation process. Favorable for off-shore } \\
\text { oil fields in terms of equipment compactness (Bienti- } \\
\text { nesi et al. 2013) }\end{array}$ \\
\hline Ultrasonic & $\begin{array}{l}\text { Low capacity and efficiency of ultrasonic cavitation } \\
\text { (Wan et al. 2019) }\end{array}$ & $\begin{array}{l}\text { *Cost-saving and environmental-friendly method } \\
\text { (Wang et al. 2020) } \\
\text { *Application while oil production operation is running } \\
\text { (Sun et al. 2011) } \\
\text { *Precise positioning of wellbore stimulation (Mohsin } \\
\text { and Meribout 2015) and stimulation for any interval } \\
\text { of interest (Meribout 2018) } \\
\text { *Suitable for high water-saturated and depleted reser- } \\
\text { voirs (Rehman and Meribout 2012) }\end{array}$ \\
\hline
\end{tabular}

which is less than 60 hertz (Hasanvand and Golparvar 2014), flows through the reservoir (Martin et al. 2017), and electrical energy is converted into heat. It can be applied in various kinds of reservoirs with various formation depths and porosities, permeabilities, temperatures, pressures, and thicknesses. (Oliveira et al. 2009; Rehman and Meribout 2012). In IH, the heat is generated as a result of hysteresis and ohmic losses in the steel casing, while in low-frequency, heat is created due to ohmic losses associated with ionic conduction through the continuous water phase (Vermeulen and McGee 2000). High-frequency electric current can be utilized for microwave (MW) heating and radio-frequency (RF) methods. At high frequencies, dielectric heating prevails where the dipoles formed by molecules tend to align themselves, resulting in rotational movement with a velocity proportional to the frequency of alteration that generates heat. The schematic of IH, low- and high-frequency heating is depicted in Fig. 2. Water saturation, salinity, and frequency are key factors in the successful implementation of EM heating (Eskandari et al. 2015). Adoption of any type of this method is dependent on reservoir fluid properties (e.g., resistivity, dielectric permittivity) and other formation
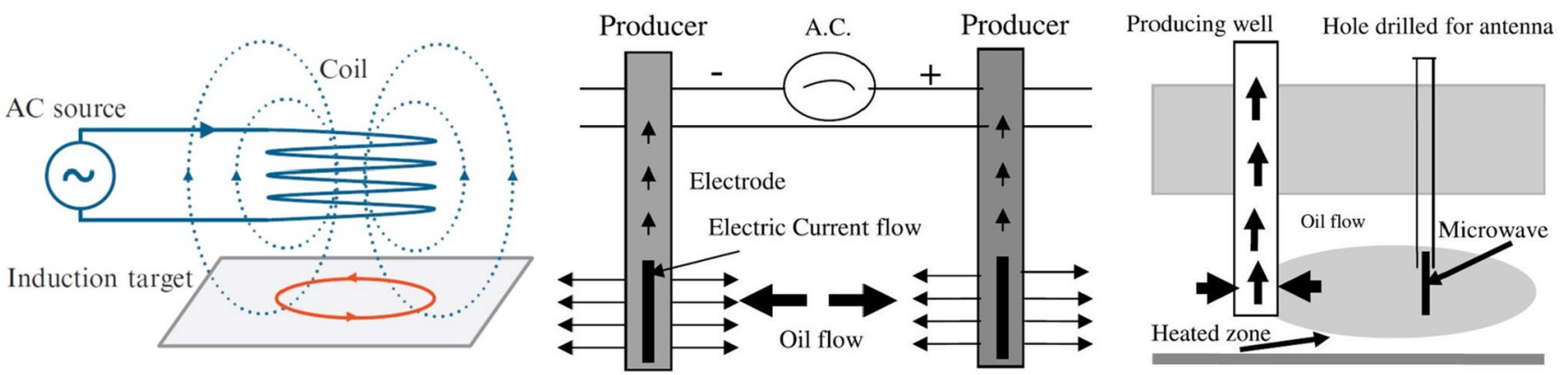

Fig. 2 Schematic of IH (Lucía et al. 2018) (left), low-frequency (middle) and high-frequency (right) (Chhetri and Islam 2008) 
characteristics (Saeedfar and Law 2018). The applied methods of EM use the physical fields of various natures rather than a substance. Adopting the EM method enables to perform heating far from its source since EM field is able to penetrate the viscous oil and the rock matrix (Zhang et al. 2018). These methods are less resource- and energy-intensive and economically more expedient compared to those used at present (Mullakaev et al. 2015), and contribute to processing time saving (Mutyala et al. 2010). EM heating can be the best alternative option wherever EOR methods cannot be implemented due to permafrost and other environmental constraints (Sahni et al. 2000). For more in-depth information regarding electrical heating methods and applications, the reader referred to Hakiki et al. (2017), Ali et al. (2020), Oloumi and Rambabu (2016), and Ramcharan and Hosein (2019).

Microwave heating is another alternative to enhance oil extraction. The range of MW (high-frequency waves with short wavelength) is between 300 and 300,000 megahertz. This method requires less power and energy and does not require any fluid to be injected. Usually, microwaves are either transmitted by a material, absorbed or reflected. In microwave heating, microwaves interact with the water molecules, which are set into circulatory motion and collide quickly with other molecules with the frequency collisions equal to the frequency of applied MWs resulting in volumetric heating (Okassa et al. 2010). The temperature rise causes the oil viscosity reduction and concurrently improvement in the oil recovery. The MW heating procedure can be influenced by different factors such as power level, standing time, cycling, applied frequency, dimensions of the cavity and position of the material (Mohsin and Meribout 2012). This technique is mostly used in the locations where conventional EOR techniques are difficult to be implemented such as shallow reservoirs (Carrizales 2010; Rehman and Meribout 2012). The advantages of MW heating for heavy oil recovery consist of high dielectric heating effect (Ovalles et al. 2002), controlled and direct way of heating of the specific area (Chakma and Jha 1992), energy and cost efficiency (Mozafari and Nasri 2017), no requirement for transportation and storage, application to heterogeneous environments, and no risk of chemical reactions with other materials found inside the reservoir, etc. Its main disadvantage is that the depth of penetration of microwaves in conductive mediums is limited (Troch et al. 1996). Therefore, when thick and heavy oil is covered by certain quantity of water, MWs will not be able to reach the oil content since they can only penetrate mostly few millimeters in the water layer (Westermark et al. 2001).

$\mathrm{RF}$ method is based on wave propagation and uses radiation of EM originated from an antenna beside an oil reservoir layer (Bera and Babadagli 2017). The range of RF is between 300 kilohertz and 300 megahertz for subsurface heating (Saeedfar et al. 2016). This method is mostly implemented to gain cumulative heavy oil around the borehole (Bientinesi et al. 2013). RF method is beneficial because of high-speed heating (Wang et al. 2019), small heat loss (Ceruttia et al. 2013; Wang et al. 2019), not much affected by geology formation, a large volume of reservoir coverage, and high efficiency in the energy generation and radiation process. (Bientinesi et al. 2013). However, it is relatively more expensive than low-frequency and IH methods (Wang et al. 2018).

Ultrasonic-based EOR is another technique for the oil extraction enhancement and/or to remove formation damage around the wellbore by supplying the mechanical vibration in elastic media. The ultrasonic is in the form of energy which is generated by a longitudinal mechanical wave with a frequency above $20 \mathrm{kHz}$. It is categorized into low frequency $(20 \mathrm{kHz}-1 \mathrm{MHz})$ and high frequency (above $1 \mathrm{MHz})$. However, high frequency of ultrasonic has a better performance compared to low frequency when the velocity of waves and their thermosonic influences are taken into account (Han 2003). Moreover, the effects of ultrasonic intensity should not be neglected since they have a proportional relationship with the enhancement of oil recovery (Westermark et al. 2001). The aim of ultrasonic waves application is to generate hydrodynamic waves downhole by providing continuous energy for dislodging trapped oil at a distance from the source.

Ultrasound waves produce vibrations in the reservoir, which would facilitate the oil production by changing the capillary forces, adhesion between rocks and fluids and cause oil coalescence (Kouznetsov et al. 1998, Hamida and Babadagli 2005a, b, c). Due to the very close acoustic impedance of water and oil, the induced energy of ultrasound waves is not heavily altered during its propagation, which depends on elasticity, size of grain, and density of the rock (Gharabi 2005), into the oil-water mixture. Hence, ultrasound waves can reduce the viscosity of heavy oil and increase oil production (Wegener et al. 2001). Oil recovery using ultrasound waves needs different equipment such as ultrasonic generator and detector, piezoelectric ceramic transducer, etc. The schematic diagram of ultrasonic-assisted oil recovery is depicted in Fig. 3. However, it is an inexpensive method due to its simple implementation. According to Wang et al. (2020), car-mounted type of equipment, currently, is mostly used in ultrasonic-assisted oil recovery projects; its only requirements are one cable car and five workers. Besides, Meribout (2018) mentioned that the cost of polymer injection device can be up to 230,000 US $\$$, while the ultrasonic device is much cheaper $(90,000$ US $\$$ ). Thus, application of this technique causes huge saving in the cost of oil recovery operations.

The ultrasonic-based EOR includes several mechanisms due to complexity of its physical process and its effects on 


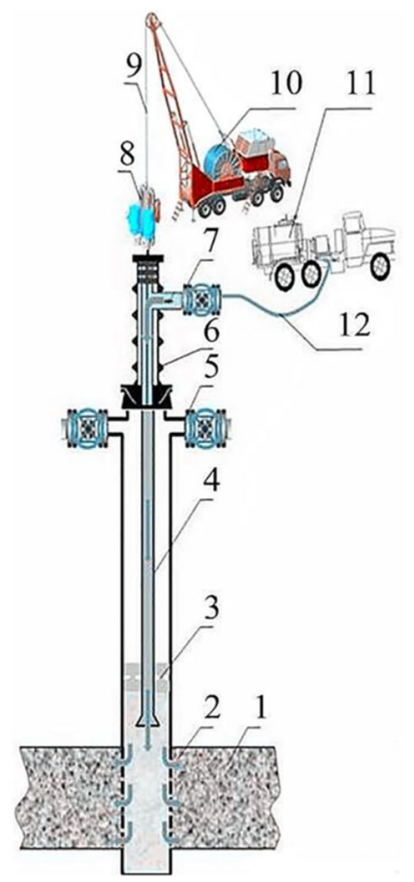

Fig. 3 Schematic diagram of ultrasonic-assisted oil recovery (Mullakaev et al. 2017): (1) oil formation; (2) ultrasonic downhole tool; (3) packer; (4) tubing; (5) casing valve; (6) lubricator; (7) discharge line; (8) umbilical cable feed; (9) umbilical cable; (10) wire line truck ПКС-5; and (11) pump unit СИН-32, 12-house

the reservoirs. One of the main mechanisms is the increase in oil viscosity reduction as a result of either mechanical vibration, cavitation (the process of the growth and collapse of liquid hollow bubbles) interaction or heating (Wang et al. 2020). The heavy oil includes small molecules that are restricted by large molecules such as colloid, long-chain free radicals, asphaltene, etc. In vibrational effect, the application of high frequency and high intensity of ultrasonic waves in elastic medium can increase the amplitude, velocity, and acceleration of elastic particles considerably. This will result in formation of strong movement between the small molecules and chains of larger molecules with great inertia, which in turn causes an increase in frictional force among molecules, breaking of the molecular chain and loosening the large molecules, and finally, reduction in heavy oil's viscosity. In cavitation effect, the application of high frequency and high intensity of ultrasonic waves causes the availability of instantaneous high temperature and high pressure due to collapse of cavitation bubbles, oxidation-reduction reaction, polymerization or depolymerization of large molecule substances, damage in the molecular chains, and subsequently, lessening of the viscosity (Shi et al. 2017; Gu et al. 2003). However, the limitations of ultrasonic cavitation are the low processing capacity and treatment efficiency (Wan et al. 2019). To mitigate this problem, they have suggested to use cavitation jet technology in which bubble collapse occurs

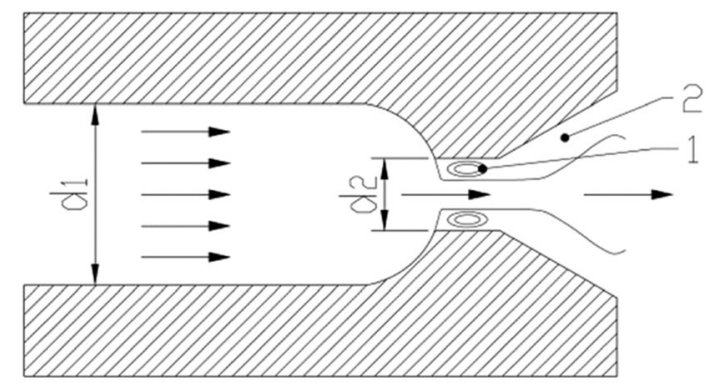

Fig. 4 Mechanism diagram of cavitation jet technology: (1) low-pressure tangential region and (2) low-pressure eddy region

when bubbles flow out of the low-pressure eddy region with the fluid, and consequently, the energy will be released because of sudden pressure growth. The mechanism diagram of cavitation jet technology is depicted in Fig. 4. In heating effect, thermal energy is produced due to absorption of ultrasonic waves inside the propagation medium. Then, oil temperature increases because of frictions at the boundary surface of different media. Finally, the heat energy will be released when cavitation bubbles collapse.

Application of ultrasonic wave includes variety of advantages such as fast and easy implementation, protection of wellbore formation against damages (Wang et al. 2020), cost-effectiveness and efficiency (Wang et al. 2020), no pollution to the reservoir (Wang et al. 2020), high compatibility with other EOR methods, variety of applications (Mohammadian et al. 2011; Zhang et al. 2013; Abramova et al. 2014; Wang et al. 2020), precise positioning of wellbore stimulation, stimulation for any interval of interest (Meribout 2018), and finally no need for chemical solvents injection such as acids (Amro et al. 2007, Sun et al. 2011). The ultrasonic-based EOR can be a very good alternative in a condition that the heavy oil is covered by the certain water quantity, in which microwaves are not able to reach the oil layer due to their limited penetration ability, because of its low alteration of energy while propagating into the mixture of oil and water (Wegener et al. 2001). The development of high-efficiency equipment, the correct selection of candidate wells, and the mathematical modeling of physical processes that accompany acoustic well stimulation are the solutions to increase the efficiency of this method substantially (Mullakaev et al. 2008, Mullakaev et al. 2009a, b, Abramov et al. 2013). The ultrasonic technique can be used in all reservoir types and may also be suitable in heterogeneous environment (Fairbanks and Chen 1970, Amro et al. 2007). A long time ago, this method has been successfully applied in a Russian oil field (Siberia) in 1990 and in oil fields of Texas and California in the USA in 1974 and 1992, respectively (Naderi and Babadagli 2010). Its most recent implementations in oil fields are summarized in Table 4.

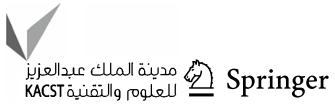


Table 4 Recent application of ultrasonic technique in oil fields

\begin{tabular}{llll}
\hline References & Country & Field name/location & Recovery rate increase \\
\hline $\begin{array}{l}\text { Abramov et al. (2013) } \\
\text { Abramova et al. (2014) }\end{array}$ & Russia & Western Siberia & Up to 50\% \\
& Russia & $\begin{array}{l}\text { Western Siberia and the } \\
\text { Samara region }\end{array}$ & Between 40 and 100\% \\
Abramov et al. (2015) & Russia & Western Siberia & 23-33 tons/day \\
Mullakaev et al. (2015) & USA & Green River Formation & Averagely, 4.45 tons/day \\
& Russia & Western Siberia & Averagely, 4.4 tons/day \\
& Russia & Samara Region & Averagely, 10.2 tons/day \\
Abramov et al. (2016) & Russia & Western Siberia & $91 \%$ \\
\hline
\end{tabular}

Except ultrasonic wave application in viscosity reduction, it has been recently applied for a variety of purposes such as size preventing paraffin precipitation (Xu et al. 2011), distribution of nanosized mist (Kudo et al. 2017), enhancing water vapor permeability (Bounos et al. 2017), cleaning turbine engines' oil filters (Nguyen et al. 2016), elimination of plugs (inorganic scales, drilling fluid, and polymer) in oil production (Taheri-Shakib et al. 2018; Wang et al. 2017), and separation of water from heavy crude oil emulsion (Antes et al. 2017).

\section{Ultrasonic-based EOR previous studies}

The history of vibration-based oil recovery studies goes back to 1950s when oil recovery increase is observed after the earthquakes occurrence and cultural noises. From that time till present, numerous studies have been conducted to investigate different aspects of ultrasonic waves implications in EOR such as ultrasonic sources, diverse fluid types, and change in influential parameters of EOR, e.g., viscosity, permeability, pressure, temperature, and interfacial tension. The first study on the application of ultrasonic waves and how they affect oil extraction is related to the study on the correlation between the water level and the stimulation caused by earthquakes (Griffing 1950). Duhon and Campbell (1965) investigated the utilization of ultrasonic waves with frequencies between 1 and 5.5 megahertz in waterflooding and concluded that ultrasonic energy enhanced the oil extraction; it causes remarkable effect on fluid displacement efficiency and negative correlation among the frequency, cavitation, and recovery. Nosov (1965) observed a decrease in the viscosity of polystyrene solution under sound waves. Fairbanks and Chen (1970) observed that the heat produced by ultrasound waves can significantly boost the percolation rate. Johnston (1971) reported that the application of ultrasonic waves reduces the surface tension and viscosity, which in turn causes oil percolation increase and subsequently enhancement in oil recovery. In a study by Gadiev (1977), ultrasound wave radiated to oil-saturated unconsolidated sand packs and it was observed that both production rate and cumulative oil production increased significantly. Neretin and Yudin (1981) observed that ultrasound waves implementation caused an increase in the oil displacement rate by water in the well's loose sands. Ganiev et al. (1989) proposed that ultrasound would deform the pore walls and alter the radius of the pore since traveling waves along pore walls may cause a "peristaltic transport" of fluid displacement. Pogosyan et al. (1989) concluded that ultrasound waves increase the gravitational separation of water and kerosene. Shaw Resource Services (1992) implemented ultrasonic radiation in two field tests in California and reported that oil extraction was boosted up to $45 \%$. Nikolaevskii (1992) observed that the ultrasonic vibrations created enable the oil drops to recover their mobility. Aarts et al. (1998) numerically and experimentally proved deformation of pore walls and fluid velocity enhancement in porous media as a result of ultrasonic radiation.

Gunal and Islam (2000) showed that ultrasonic treatments do not change crude oil rheology as a function of temperature. Guo et al. (2004) applied ultrasonic waves to oil fields in China and observed an increase in oil production. Hamida and Babadagli (2005a, b, c) examined the influence of ultrasonic wave on capillary imbibition and concluded that matrix-fracture interaction type and capillary imbibition depending on the fluid may cause oil recovery enhancement when ultrasonic waves are applied. Hamida and Babadagli (2005a), Hamida and Babadagli (2007a, b, c), and Hamida and Babadagli (2007a) investigated the capillary interaction between the matrix and fracture under different ultrasonic intensities for different fluid types. The results of their experiments indicated that the application of ultrasonic energy may increase the surfactant solubility and the rheological properties of polymers may be altered. Amro et al. (2007) conducted experiments to investigate the effect of ultrasound waves on the movement of additional oil in reservoir. The wave stimulation experiments showed that oil recovery enhanced in both horizontal and vertical corefloods. In a study by Hamida and Babadagli (2007b), the influence of high-frequency, high-intensity ultrasonic radiation at the interface between immiscible and miscible fluids was analyzed. They found that ultrasound acts to stabilize 
the interfacial front and that such effect is most pronounced at low viscosity ratios. Hamida and Babadagli (2008a, b) adopted the pendant drop method to investigate the effect of ultrasound on flow through a capillary. They found a remarkable change in the interfacial forces between oil and water. Hamida and Babadagli (2008a) analyzed the influence of high-frequency and high-intensity ultrasonic radiation on the immiscible and miscible displacement. Miscible experiments showed that the ultrasonic radiation enhances molecular diffusion and causes little change in both fractal dimension and lacunarity at low and higher injection rates, respectively. The experiments by Naderi and Babadagli (2008a, 2010) stated that ultrasonic radiation increases the recovery and has a significant influence on oil-wet samples.

Najafi (2010) analytically and experimentally investigated the effect of ultrasound on gravity drainage and percolation of oil by using fluids of different viscosities. They concluded that the radiation acts in opposition to capillary pressure effect. Mohammadian et al. (2011) experimentally found that the recovery of waterflooding increased as a result of ultrasonic stimulation. Mohammadian et al. (2013) investigated the effects of sonication radiation on oil recovery by ultrasonic waves-stimulated waterflooding. Their experiments indicated that the recovery of waterflooding increased for all cases. Abramov et al. (2013) and Mohsin and Meribout (2015) suggested a new method for the ultrasonic-based EOR. Alhomadhi et al. (2014) investigated the ability of ultrasound waves to mobilize additional oil. They observed an increase in the rate of oil displacement. Abramova et al. (2014) developed ultrasonic equipment and tested it in two different regions in different geological conditions. They observed significant improvement in oil production. The study by Keshavarzi et al. (2014) stated that the recovery factor of the free gravity drainage process of the oil highly increased under radiation of ultrasound waves. Gao et al. (2015) examined the effect of different frequencies of ultrasonic on different oil components elimination from oily sludge. They found that the highest efficiency and oil recovery rate were achieved when the ultrasonic washing with a frequency of $25 \mathrm{kHz}$ is applied. Hamidi et al. (2015) revealed that emulsification could be one of the most important oil recovery mechanisms happening in porous media when ultrasound is applied for a short time. Furthermore, the ultrasound radiation time increase causes an increase in size and decrease in the dispersed phase droplets stability. Mullakaev et al. (2017) conducted field experiments in Western Siberia and developed the ultrasonic automated oil well complex. The result of tests showed a noticeable boost in the oil production rate and average well productivity. Arabzadeh and Amani (2017) assessed the effect of ultrasonic wave on the oil permeability of three samples with different average bead sizes and its influence on oil recovery in terms of free fall gravity drainage. They found that using sonication, bigger bead sizes result in more oil recovery in nonasphaltenic samples and reduce the gravity drainage in the asphaltenic samples. Furthermore, their results reveal that sonication enhances the recovery in the gravity drainage process, while it has a negative impact on asphaltenic samples by means of oil viscosity increment. Shi et al. (2017) experimentally studied the effect of the ultrasonic application on reducing the viscosity of crude oil samples from the Daqing oil field. They found that the ultrasonic technique is beneficial to depolymerizing and breaking the long chains of large molecules (resin and asphaltene), and it has a considerable influence on decreasing the thermal energy consumption in the process. He et al. (2018b) explored the effectiveness of different soil types, oil components, and ultrasonic operation factors on oil recovery from heavy oilcontaining sludge. Their results state that ultrasonic power and hydrophilicity of sludge are the most significant factors affecting the efficiency of heavy oil recovery. Abdulfatah (2018) implemented ultrasound waves in reservoirs, and the result of his experiments yielded up to $50 \%$ increase in oil recovery. The summary of previous studies on ultrasonicbased EOR from 2000 onward is mentioned in Table 5.

\section{Discussion}

This study reviewed the application of conventional EOR techniques as well as EEOR methods with more focus on ultrasonic-assisted oil recovery. The following discusses the most suitable/efficient techniques for the ultrasonic-based EOR. The ultrasonic stimulation can highly assist in waterflooding method to increase the recovery rate. Using lowviscous high-API fluid such as kerosene causes low mobility ration and high sweep efficiency, and consequently, the recovery rate of ultrasonic-stimulated waterflooding will be high. Similarly, $\mathrm{CO}_{2}$ flooding under both controlled and uncontrolled temperature conditions can be aided by ultrasonic stimulation. In fact, in ultrasound-assisted $\mathrm{CO}_{2}$ flooding technique, the parameters such as viscosity, capillary pressure, and interfacial tension will be reduced to improve the oil recovery. The ultrasonic downhole stimulation can be used to revitalize the failing oil wells and increase their production rate. Ultrasonic treatment is highly effective on wells with permeability above $20 \mathrm{mD}$ and porosity higher than $15 \%$. In the case of wells with lower permeability and porosity, ultrasound should be combined with chemicals to boost the production rate of the well. The wettability of rocks influences the effectiveness of ultrasonic radiation. Employing ultrasound waves can boost oil recovery in both water-wet and oil-wet cases. However, water-wet cases show a slight increase in ultimate recovery, while oil-wet cases experience high rate of ultimate recovery. Thus, oil-wet cases are more suitable than water-wet cases for ultrasound application.

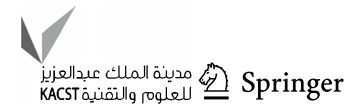




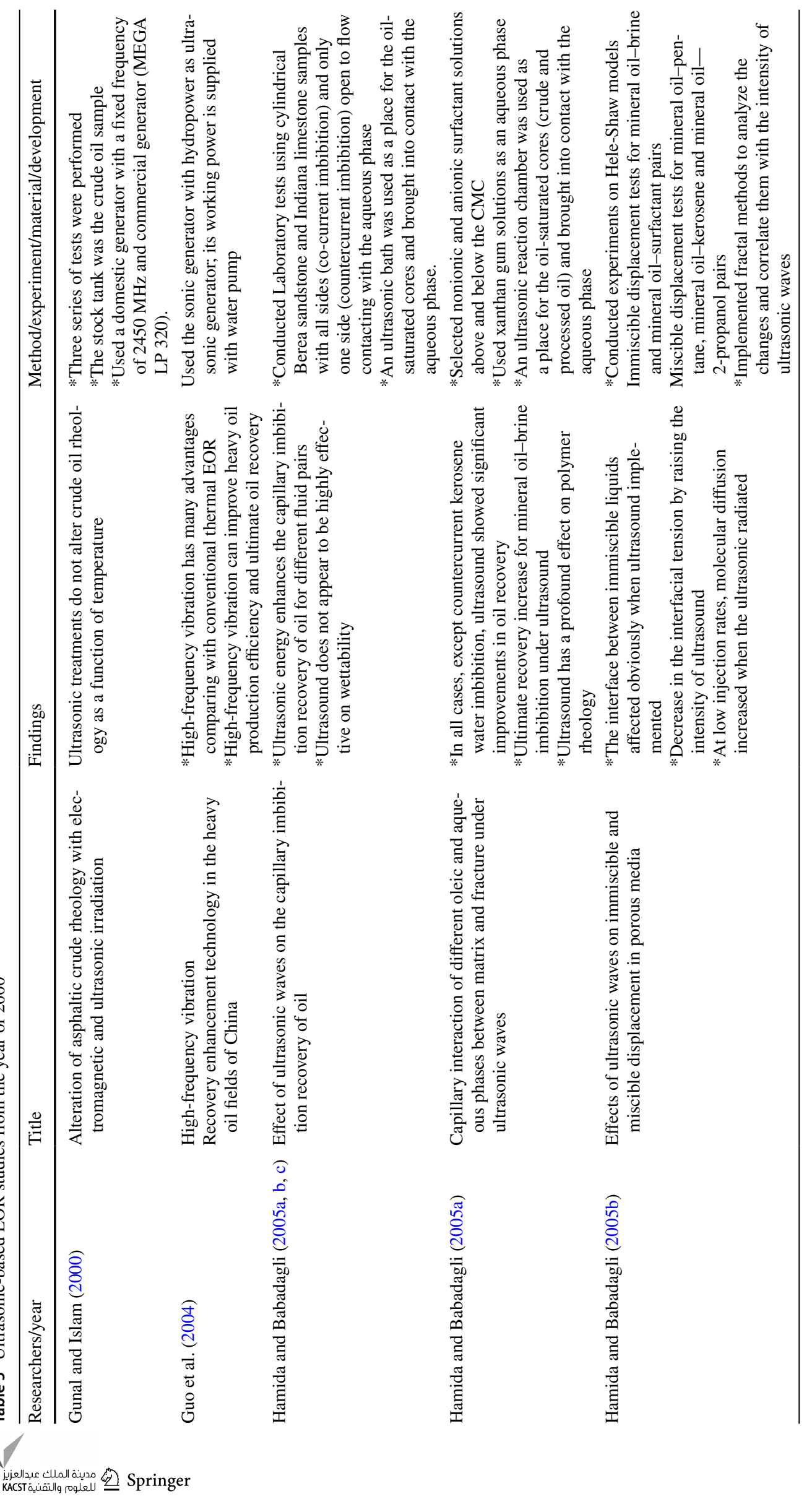




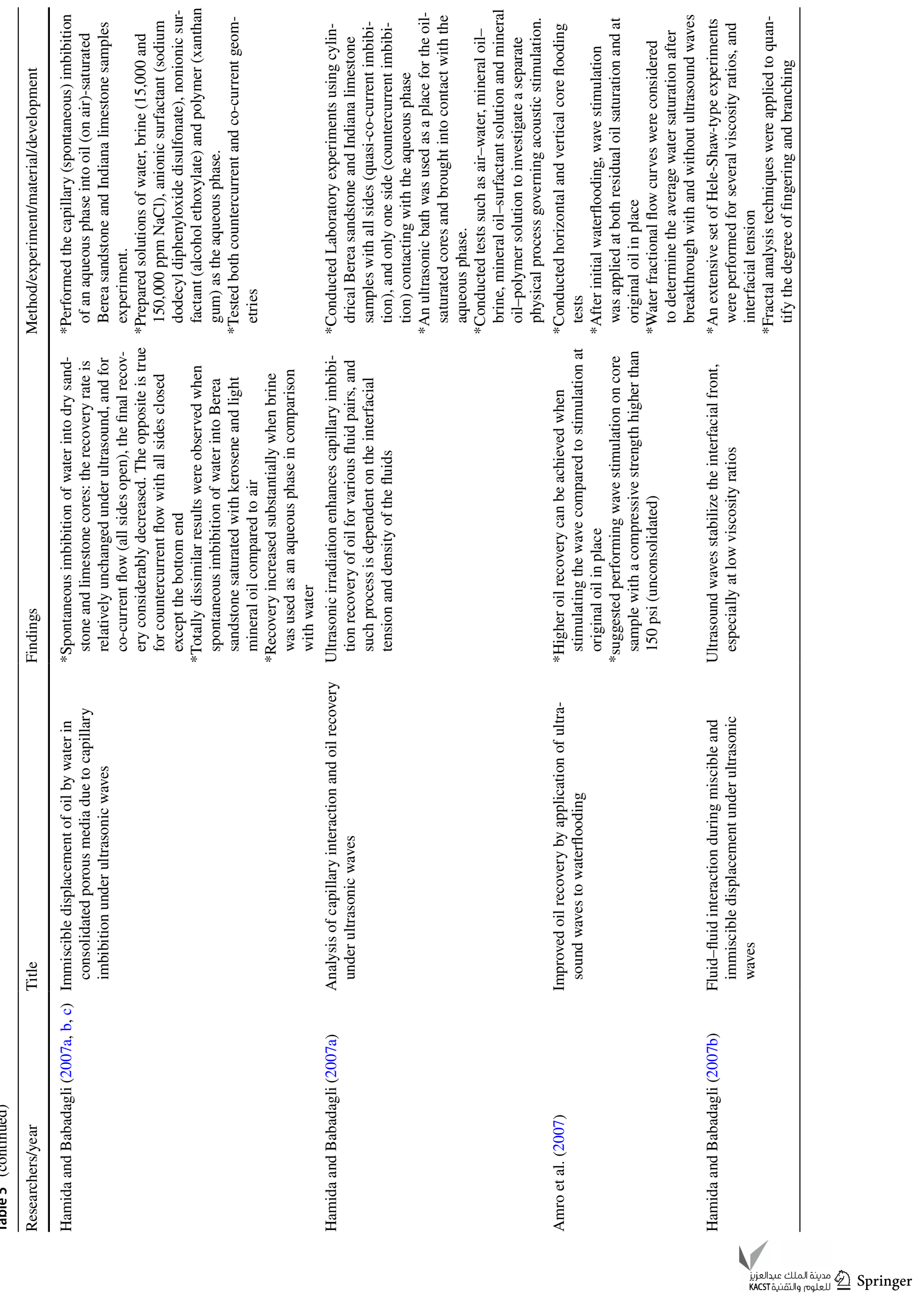




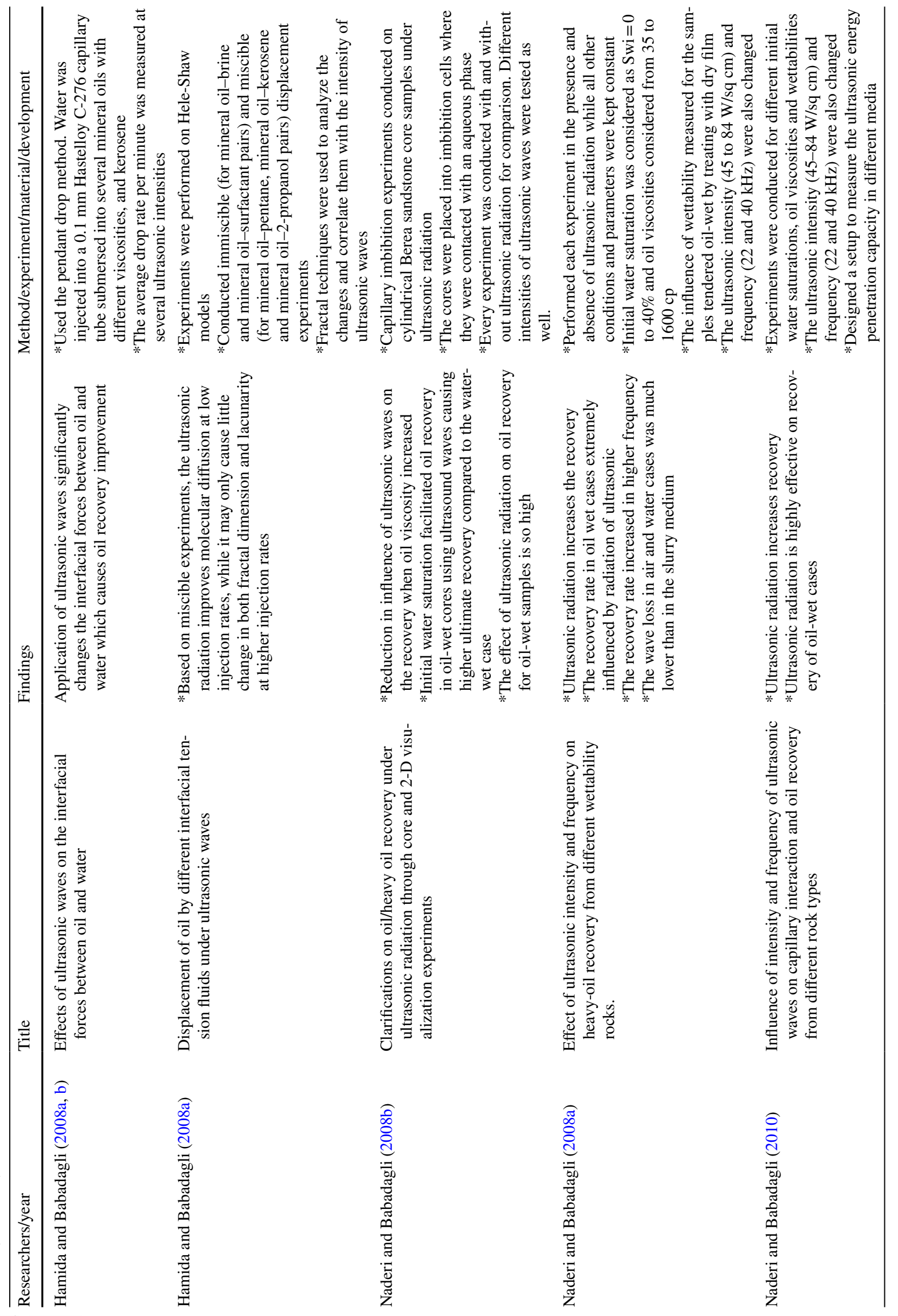




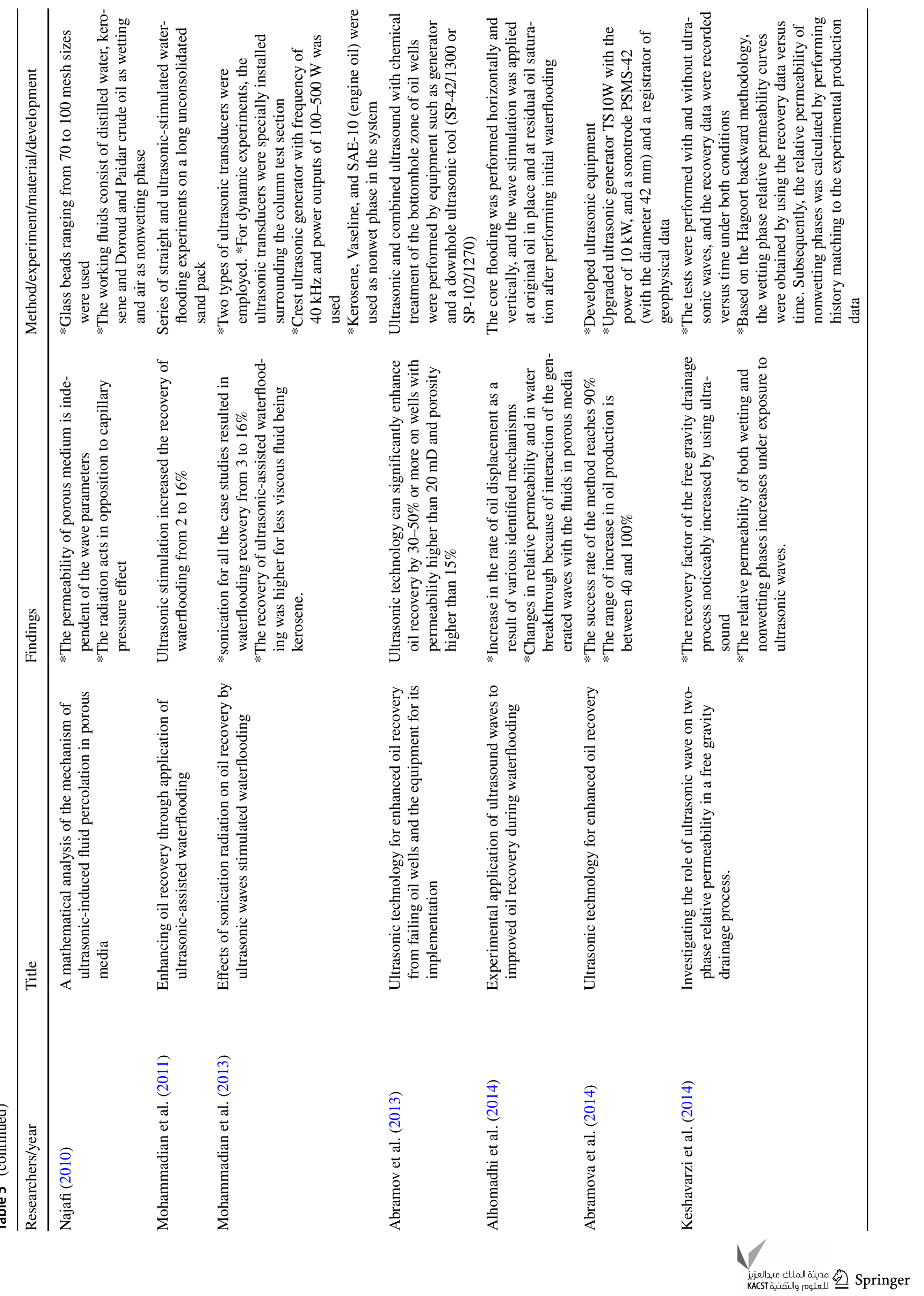




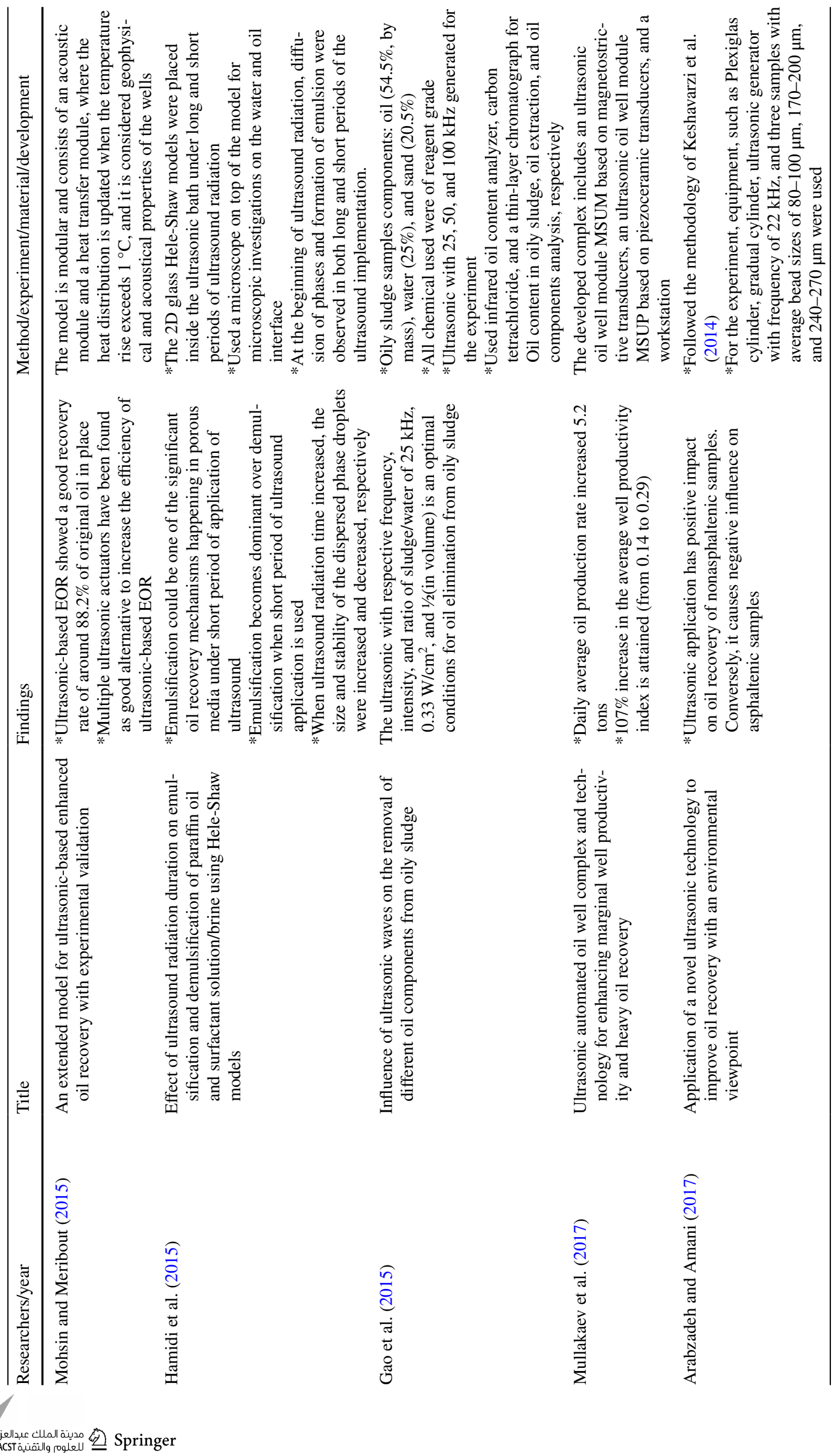




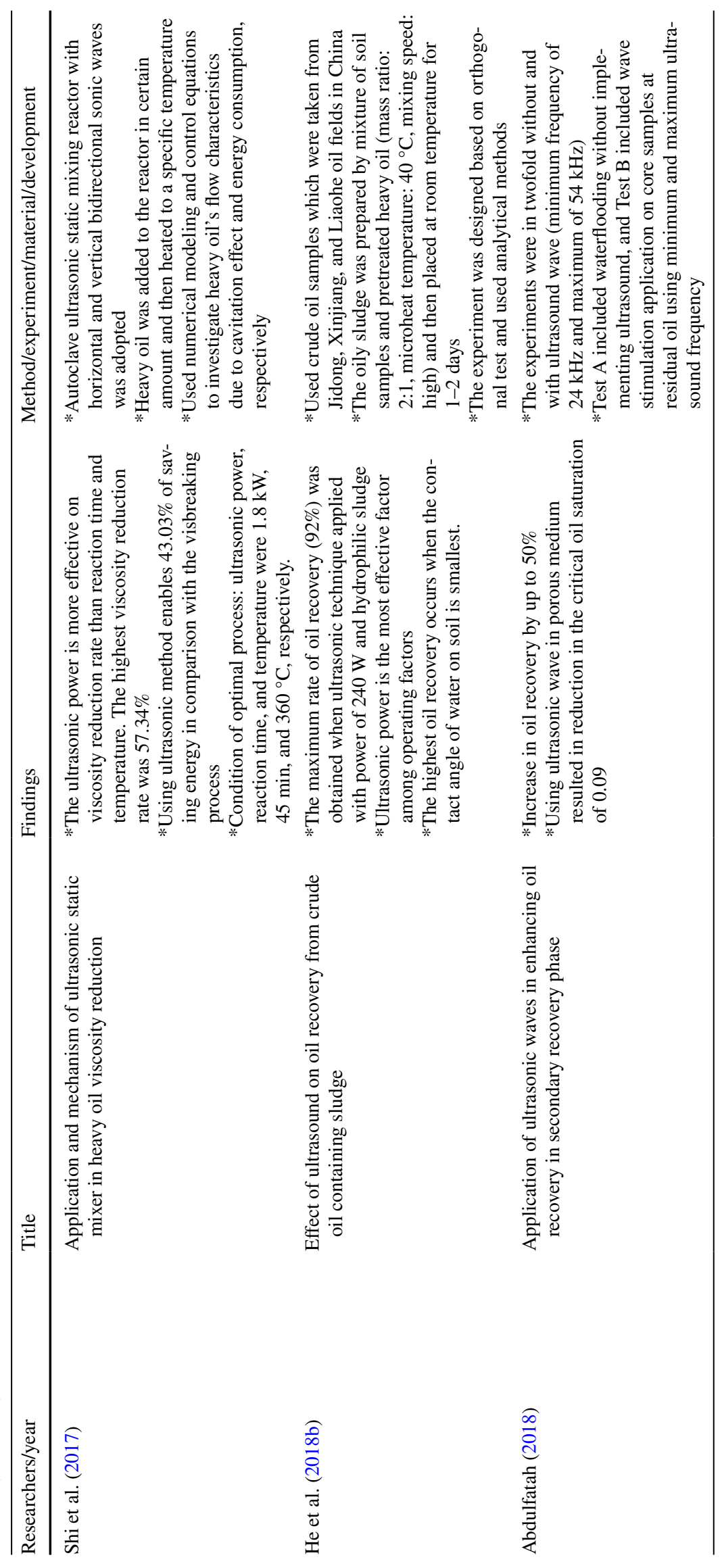


Ultrasound waves influence the interface between immiscible liquids by enhancing momentum and heat transfer across the phase interfaces. When the ultrasound intensity is increased, the interfacial tension decreases.

\section{Conclusions}

A review has been executed to investigate the trend of employing ultrasonic waves for enhanced oil recovery. Variety of related experimental studies and field applications in different locations were performed during past decades considering effects of ultrasound waves on influential parameters of enhanced oil recovery. For several reasons, adoption of ultrasonic waves for enhanced oil recovery is beneficial. Firstly, it is an economical and environmentally friendly method. Secondly, it can be implemented in any reservoir type and significantly boost the oil production rate. Thirdly, it will keep the well and its casing is safe and it removes formation damage around the wellbore. Additionally, it allows stimulation for any interval of interest and prevents heat loss. To conclude, employing ultrasonic waves for EOR has shown promising results recently and it provides EOR scientists with an interesting and challenging field of study.

Open Access This article is licensed under a Creative Commons Attribution 4.0 International License, which permits use, sharing, adaptation, distribution and reproduction in any medium or format, as long as you give appropriate credit to the original author(s) and the source, provide a link to the Creative Commons licence, and indicate if changes were made. The images or other third party material in this article are included in the article's Creative Commons licence, unless indicated otherwise in a credit line to the material. If material is not included in the article's Creative Commons licence and your intended use is not permitted by statutory regulation or exceeds the permitted use, you will need to obtain permission directly from the copyright holder. To view a copy of this licence, visit http://creativecommons.org/licenses/by/4.0/.

\section{References}

Aarts A, Ooms G, Bil K, Bot E (1998) Enhancement of liquid flow through a porous medium by ultrasonic radiation. In: European petroleum conference. Society of Petroleum Engineers

Abdulfatah HK (2018) Application of ultrasonic waves in enhancing oil recovery in secondary recovery phase. In: SPE annual technical conference and exhibition. Society of Petroleum Engineers

Abramov VO, Mullakaev MS, Abramova AV, Esipov IB, Mason TJ (2013) Ultrasonic technology for enhanced oil recovery from failing oil wells and the equipment for its implementation. Ultrason Sonochem 20(5):1289-1295

Abramov VO, Abramova AV, Bayazitov VM, Altunina LK, Gerasin AS, Pashin DM, Mason TJ (2015) Sonochemical approaches to enhanced oil recovery. Ultrason Sonochem 25:76-81

Abramov VO, Abramova AV, Bayazitov VM, Marnosov AV, Kuleshov SP, Gerasin AS (2016) Selective ultrasonic treatment of perforation zones in horizontal oil wells for water cut reduction. Appl Acoust 103:214-220
Abramova A, Abramov V, Bayazitov V, Gerasin A, Pashin D (2014) Ultrasonic technology for enhanced oil recovery. Sci Res Eng 6(04):177-184

Acar Ç (2007) Enhancing petroleum recovery from heavy oil fields by microwave heating. Middle East Technical University, Ankara

Al-Anazi BD (2007) Enhanced oil recovery techniques and nitrogen injection. CSEG Rec 32(8):29-33

Alfazazi U, AlAmeri W, Hashmet MR (2019) Experimental investigation of polymer flooding with low-salinity preconditioning of high temperature-high-salinity carbonate reservoir. J Pet Explor Prod Technol 9(2):1517-1530

Alhomadhi E, Amro M, Almobarky M (2014) Experimental application of ultrasound waves to improved oil recovery during waterflooding. J King Saud Univ Eng Sci 26(1):103-110

Ali H, Soleimani H, Yahya N, Khodapanah L, Sabet M, Demiral BM, Hussain T, Lanre AL (2020) Enhanced oil recovery by using electromagnetic-assisted nanofluids: a review. J Mol Liq 309:113095

Almansour AO, AlQuraishi AA, AlHussinan SN, AlYami HQ (2017) Efficiency of enhanced oil recovery using polymeraugmented low salinity flooding. J Pet Explor Prod Technol 7(4):1149-1158

Al-Saedi HN, Flori RE, Al-Jaberi SK (2019) Eliminate the role of clay in sandstone: EOR low salinity water flooding. J Pet Explor Prod Technol 9(2):1475-1483

Al-Sarihi A, Zeinijahromi A, Genolet L, Behr A, Kowollik P, Bedrikovetsky P (2018) Effects of fines migration on residual oil during low-salinity waterflooding. Energy Fuels 32(8):8296-8309

Al-Sayegh A, Al-Wahaibi Y, Al-Bahry S, Elshafie A, Al-Bemani A, Joshi S (2017) Enhanced oil recovery using biotransformation technique on heavy crude oil. Int J 13(36):75-79

Alvarado V, Manrique E (2010) Enhanced oil recovery: an update review. Energies 3:1529-1575

Amro MA, Mobarky MA, Al-Homadhi ES (2007) Improved oil recovery by application of sound waves to waterflooding. In: SPE middle east oil and gas show and conference. Society of Petroleum Engineers

Andrei M, Simoni M, Delbianco A, Cazzani P (2010) Enhanced oil recovery with $\mathrm{CO}_{2}$ capture and sequestration. Congress Paper, Eni

Antes FG, Diehl LO, Pereira JS, Guimarães RC, Guarnieri RA, Ferreira BM, Flores EM (2017) Effect of ultrasonic frequency on separation of water from heavy crude oil emulsion using ultrasonic baths. Ultrason Sonochem 35:541-546

Arabzadeh H, Amani M (2017) Application of a novel ultrasonic technology to improve oil recovery with an environmental viewpoint. J Pet Environ Biotechnol 8(02):1-5

Archer JS, Wall CG (2012) Petroleum engineering: principles and practice. Springer, London

Austad T, RezaeiDoust A, Puntervold T (2010) Chemical mechanism of low salinity water flooding in sandstone reservoirs. In: SPE improved oil recovery symposium. Society of Petroleum Engineers, 24-28 April, Tulsa, Oklahoma, USA. https://doi. org/10.2118/129767-MS

Ayatollahi S, Zerafat MM (2012) Nanotechnology-assisted EOR techniques: new solutions to old challenges. In: Proceedings of the SPE international oilfield nanotechnology conference and exhibition, Noordwijk, The Netherlands, 12-14 June 2012

Ayirala S, Yousef A (2015) A state-of-the-art review to develop injection-water-chemistry requirement guidelines for IOR/EOR projects. SPE Prod Oper 30(01):26-42

Azam MR, Tan IM, Ismail L, Mushtaq M, Nadeem M, Sagir M (2013) Static adsorption of anionic surfactant onto crushed Berea sandstone. J Pet Explor Prod Technol 3(3):195-201

Bachu S, Adams J (2003) Sequestration of $\mathrm{CO}_{2}$ in geological media in response to climate change: capacity of deep saline 
aquifers to sequester $\mathrm{CO}_{2}$ in solution. Energy Convers Manag 44(20):3151-3175

Bahadori A (2018) Fundamentals of enhanced oil and gas recovery from conventional and unconventional reservoirs. Gulf Professional Publishing, Houston

Banerjee S, Hascakir B (2018) Design of flow control devices in steamassisted gravity drainage (SAGD) completion. J Pet Explor Prod Technol 8(3):785-797

Belazreg L, Mahmood SM, Aulia A (2019) Novel approach for predicting water alternating gas injection recovery factor. J Pet Explor Prod Technol 9(4):2893-2910

Bera A, Babadagli T (2017) Effect of native and injected nano-particles on the efficiency of heavy oil recovery by radio frequency electromagnetic heating. J Pet Sci Eng 153:244-256

Bernard GG (1967) Effect of floodwater salinity on recovery of oil from cores containing clays. In: Thirty-eight annual California regional meeting of SPE, Los Angeles, California. https://doi. org/10.2118/1725-MS

Bientinesi M, Petarca L, Cerutti A, Bandinelli M, De Simoni M, Manotti M, Maddinelli G (2013) A radiofrequency/microwave heating method for thermal heavy oil recovery based on a novel tight-shell conceptual design. J Pet Sci Eng 107:18-30

Bounos G, Andrikopoulos KS, Moschopoulou H, Lainioti GC, Roilo D, Checchetto R, Voyiatzis GA (2017) Enhancing water vapor permeability in mixed matrix polypropylene membranes through carbon nanotubes dispersion. J Membr Sci 524:576-584

Buenaventura JE, Alvarez RS, Flores JG, Martinez IE (2014) Gas injection enhanced oil recovery application in a mature naturallyfractured-carbonate reservoir. In: SPE Latin America and Caribbean petroleum engineering conference. Society of Petroleum Engineers

Câmara JMDA, Sousa MASB, Neto EB, Oliveira MCA (2019) Application of rhamnolipid biosurfactant produced by Pseudomonas aeruginosa in microbial-enhanced oil recovery (MEOR). J Pet Explor Prod Technol 9(3):2333-2341

Carrizales MA (2010) Recovery of stranded heavy oil by electromagnetic heating. Doctoral dissertation

Carrizales M, Lake LW (2009) Two-dimensional COMSOL simulation of heavy-oil recovery by electromagnetic heating. In: COMSOL conference held in Boston, Massachusetts, USA

Carrizales MA, Lake L, Johns RT (2008) Production improvement of heavy-oil recovery by using electromagnetic heating. In: SPE annual technical conference and exhibition. Society of Petroleum Engineers

Ceruttia A, Bandinellia M, Bientinesib M, Petarcac L, De Simonid M, Manottid M, Maddinellid G (2013) A new technique for heavy oil recovery based on electromagnetic heating: system design and numerical modelling. Chem Eng Trans 32:1255

Chakma A, Jha KN (1992) Heavy-oil recovery from thin pay zones by electromagnetic heating. In: SPE annual technical conference and exhibition, Washington, D.C. Society of Petroleum Engineers

Chavan M, Dandekar A, Patil S, Khataniar S (2019) Low-salinity-based enhanced oil recovery literature review and associated screening criteria. Pet Sci 16:1344-1360

Chen J, Hirasaki GJ, Flaum M (2006) NMR wettability indices: effect of OBM on wettability and NMR responses. J Pet Sci Eng 52(1-4):161-171

Chhetri AB, Islam MR (2008) A critical review of electromagnetic heating for enhanced oil recovery. Pet Sci Technol 26(14):1619-1631

Chierici GL (2012) Principles of petroleum reservoir engineering. Springer, Berlin

Clark B (2007) Heavy oil. Working document of the NPC Global Oil and gas study

Cui Q (2017) Recent progress in MEOR technology in low-medium permeability reservoirs. In: Proceedings of 7th chemical flooding enhanced oil recovery conference. Chinese Petroleum Society, pp. 1-9, Dalian, Liaoning Province, China

Dang TQC, Chen Z, Nguyen TBN, Bae W (2014) The potential of enhanced oil recovery by micellar/polymer flooding in heterogeneous reservoirs. Energy Sources Part A Recov Util Environ Effects 36(14):1540-1554

Dang Cuong, Nghiem Long, Nguyen Ngoc, Yang Chaodong, Chen Zhangxin, Bae Wisup (2018) Modeling and optimization of alkaline-surfactant-polymer flooding and hybrid enhanced oil recovery processes. J Pet Sci Eng 169:578-601

Duhon R, Campbell J (1965) The effect of ultrasonic energy on flow through porous media. In: 2nd Annual eastern regional meeting of SPE/AIME. Society of Petroleum Engineers SPE

Eghbali S, Ayatollahi S, Boozarjomehry RB (2016) New expert system for enhanced oil recovery screening in non-fractured oil reservoirs. Fuzzy Sets Syst 293:80-94

El-Hoshoudy AN, Desouky S (2018) $\mathrm{CO}_{2}$ miscible flooding for enhanced oil recovery. Carbon Capture, Utilization and Sequestration 79

Eskandari S, Jalalalhosseini S, Mortezazadeh E (2015) Microwave heating as an enhanced oil recovery method-potentials and effective parameters. Energy Sources Part A Recovery Util Environ Effects 37(7):742-749

Fairbanks H, Chen W (1970) Ultrasonic acceleration of liquid flow through porous media. In: AIChE symposium series (United States), West Virginia University

Fanchi JR (2018) Principles of applied reservoir simulation, 4th edn. Gulf Professional Publishing, Houston

Fredriksen SB, Rognmo AU, Sandengen K, Fernø MA (2017) Wettability effects on osmosis as an oil-mobilization mechanism during low-salinity waterflooding. Petrophysics 58(01):28-35

Gadiev S (1977) Use of vibrations in oil production. Nedra, Moscow

Ganiev R, Ukrainskii L, Frolov K (1989) Wave mechanism for the acceleration of a liquid flowing in capillaries and porous media. Soviet Physics Doklady

Gao C (2018) Experiences of microbial enhanced oil recovery in Chinese oil fields. J Pet Sci Eng 166:55-62

Gao Y, Ding R, Wu S, Wu Y, Zhang Y, Yang M (2015) Influence of ultrasonic waves on the removal of different oil components from oily sludge. Environ Technol 36(14):1771-1775

Gbadamosi AO, Kiwalabye J, Junin R, Augustine A (2018) A review of gas enhanced oil recovery schemes used in the North Sea. J Pet Explor Prod Technol 8(4):1373-1387

Gbadamosi AO, Junin R, Manan MA, Agi A, Yusuff AS (2019) An overview of chemical enhanced oil recovery: recent advances and prospects. Int Nano Lett 9:171-202

Ghalenavi H, Norouzi-Apourvari S, Schaffie M, Ranjbar M (2020) Significant effect of compositional grading on SAGD performance in a fractured carbonate heavy oil reservoir. J Pet Explor Prod Technol 10(3):903-910

Gharabi R (2005) Application of an expert system to optimize reservoir performance. J Pet Sci Eng 49(3-4):261-273

Godec M, Kuuskraa V, van Leeuwen T, Melzer LS, Wildgust N (2011) $\mathrm{CO}_{2}$ storage in depleted oil fields: the worldwide potential for carbon dioxide enhanced oil recovery. Energy Procedia 4:2162-2169

Goswami R, Chaturvedi KR, Kumar RS, Chon BH, Sharma T (2018) Effect of ionic strength on crude emulsification and EOR potential of micellar flood for oil recovery applications in high saline environment. J Pet Sci Eng 170:49-61

Green DW, Willhite GP (1998) Enhanced oil recovery, Henry L Doherty Memorial Fund of AIME. Society of Petroleum Engineers, Richardson

Griffing V (1950) Theoretical explanation of the chemical effects of ultrasonics. J Chem Phys 18(7):997-998

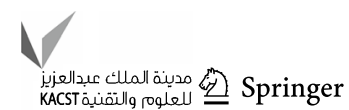


Gu C, Yu J, Ren Y (2003) Study and application of ultrasonic oil production technique. Oil Drill Prod Technol 26(6):59-61

Gunal OG, Islam M (2000) Alteration of asphaltic crude rheology with electromagnetic and ultrasonic irradiation. J Pet Sci Eng 26(1-4):263-272

Guo X, Du Z, Li G, Shu Z (2004) High frequency vibration recovery enhancement technology in the heavy oil fields of China. In: SPE international thermal operations and heavy oil symposium and western regional meeting. Society of Petroleum Engineers

Haghighi OM, Firozjaii AM (2019) An experimental investigation into enhancing oil recovery using combination of new green surfactant with smart water in oil-wet carbonate reservoir. J Pet Explor Prod Technol 1-9

Hakiki F, Salam DD, Akbari A, Nuraeni N, Aditya W, Siregar S (2015a) Is epoxy-based polymer suitable for water shut-off application? In: SPE/IATMI Asia pacific oil \& gas conference and exhibition. Society of Petroleum Engineers

Hakiki F, Maharsi DA, Marhaendrajana T (2015b) Surfactant-polymer coreflood simulation and uncertainty analysis derived from laboratory study. J Eng Technol Sci 47(6):706-725

Hakiki F, Aditya A, Ulitha DT, Shidqi M, Adi WS, Wibowo KH, Barus M (2017) Well and inflow performance relationship for heavy oil reservoir under heating treatment. Society of Petroleum Engineers. 186187-MS

Hamida T, Babadagli T (2005a) Effect of ultrasonic waves on the capillary imbibition recovery of oil. In: SPE Asia pacific oil and gas conference and exhibition. Society of Petroleum Engineers

Hamida T, Babadagli T (2005b) Capillary interaction of different oleic and aqueous phases between matrix and fracture under ultrasonic waves. In: SPE Europec/EAGE annual conference. Society of Petroleum Engineers

Hamida T, Babadagli T (2005c) Effects of ultrasonic waves on immiscible and miscible displacement in porous media. In: SPE annual technical conference and exhibition. Society of Petroleum Engineers

Hamida T, Babadagli T (2007a) Immiscible displacement of oil by water in consolidated porous media due to capillary imbibition under ultrasonic waves. J Acoust Soc Am 122(3):1539-1555

Hamida T, Babadagli T (2007b) Analysis of capillary interaction and oil recovery under ultrasonic waves. Transp Porous Media 70(2):231-255

Hamida T, Babadagli T (2007c) Fluid-fluid interaction during miscible and immiscible displacement under ultrasonic waves. Eur Phys J B 60(4):447-462

Hamida T, Babadagli T (2008a) Effects of ultrasonic waves on the interfacial forces between oil and water. Ultrason Sonochem 15(4):274-278

Hamida T, Babadagli T (2008b) Displacement of oil by different interfacial tension fluids under ultrasonic waves. Colloids Surf A 316(1-3):176-189

Hamidi H, Mohammadian E, Asadullah M, Azdarpour A, Rafati R (2015) Effect of ultrasound radiation duration on emulsification and demulsification of paraffin oil and surfactant solution/brine using Hele-Shaw models. Ultrason Sonochem 26:428-436

Han X (2003) Frequency dependence of the thermosonic effect. Rev Sci Instrum 74(1):414-416

Hartono AD, Hakiki F, Syihab Z, Ambia F, Yasutra A, Sutopo S, Efendi M, Sitompul V, Primasari I, Apriandi R (2017) Revisiting EOR projects in indonesia through integrated study: EOR screening, predictive model, and optimisation, Jakarta, Indonesia

Haq B, Liu J, Liu K, Malaki E, Al-Shehri D (2019) Modification of eclipse simulator for microbial enhanced oil recovery. J Pet Explor Prod Technol 9(3):2247-2261

Hasanvand MZ, Golparvar A (2014) A critical review of improved oil recovery by electromagnetic heating. Pet Sci Technol 32(6):631-637
Hascakir B, Babadagli T, Akin S (2008) Experimental and numerical modeling of heavy-oil recovery by electrical heating. In: International thermal operations and heavy oil symposium. Society of Petroleum Engineers

He J, Wang Y, Liang G (2018a) Emerging strategic technology of the oilfield development. Petroleum Industry Press, Beijing

He S, Tan X, Hu X, Gao Y (2018b) Effect of ultrasound on oil recovery from crude oil containing sludge. Environ Technol 40(11):1401-1407

Hite JR, Bondor PL (2004) Planning EOR projects. In: SPE international petroleum conference in Mexico. Society of Petroleum Engineers

Ismail WA, Van Hamme JD, Kilbane JJ, Gu JD (2017) Petroleum microbial biotechnology: challenges and prospects. Front Microbiol 8:833

Jeong C, Kallivokas L, Kucukcoban S, Deng W, Fathi A (2015) Maximization of wave motion within a hydrocarbon reservoir for wave-based enhanced oil recovery. J Pet Sci Eng 129:205-220

Jia B, Tsau JS, Barati R (2019) A review of the current progress of $\mathrm{CO}_{2}$ injection EOR and carbon storage in shale oil reservoirs. Fuel 236:404-427

Johnston H (1971) II. Polymer viscosity control by the use of ultrasonics. In: Chemical engineering progress symposium series

Kamari A, Mohammadi AH (2014) Screening of enhanced oil recovery methods. Handbook on oil production research Nova Science Publishers Inc, USA

Kamari A, Nikookar M, Hemmati-Sarapardeh A, Sahranavard L, Mohammadi AH (2015) Screening of potential application of EOR processes in a naturally fractured oil reservoir. Enhanced oil recovery, chapter 11. Nova Science Publishers, Hauppauge

Kang PS, Lim JS, Huh C (2016) Screening criteria and considerations of offshore enhanced oil recovery. Energies 9(1):44

Katende A, Sagala F (2019) A critical review of low salinity water flooding: mechanism, laboratory and field application. J Mol Liq 278:627-649

Ke CY, Sun WJ, Li YB, Hui JF, Lu GM, Zheng XY, Zhang QZ, Zhang XL (2018a) Polymer-assisted microbial-enhanced oil recovery. Energy Fuels 32(5):5885-5892

Ke CY, Lu GM, Li YB, Sun WJ, Zhang QZ, Zhang XL (2018b) A pilot study on large-scale microbial enhanced oil recovery (MEOR) in Baolige Oilfield. Int Biodeterior Biodegrad 127:247-253

Keshavarzi B, Karimi R, Najafi I, Ghazanfari M, Ghotbi C (2014) Investigating the role of ultrasonic wave on two-phase relative permeability in a free gravity drainage process. Sci Iran Trans C Chem Chem Eng 21(3):763

Khojastehmehr M, Madani M, Daryasafar A (2019) Screening of enhanced oil recovery techniques for Iranian oil reservoirs using TOPSISalgorithm. Energy Rep 5:529-544. https://doi. org/10.1016/j.egyr.2019.04.011

Kong X, Ohadi M (2010) Applications of micro and nano technologies in the oil and gas industry-overview of the recent progress. In: Proceedings of the Abu Dhabi international petroleum exhibition \& conference, Abu Dhabi, UAE, 1-4 November 2010

Kouznetsov O, Simkin E, Chilingar G, Katz S (1998) Improved oil recovery by application of vibro-energy to waterflooded sandstones. J Pet Sci Eng 19(3-4):191-200

Kudo T, Sekiguchi K, Sankoda K, Namiki N, Nii S (2017) Effect of ultrasonic frequency on size distributions of nanosized mist generated by ultrasonic atomization. Ultrason Sonochem 37:16-22

Kulkarni MM (2003) Immiscible and miscible gas-oil displacements in porous media. Master's Thesis, Louisiana State University, Baton Rouge, LA, USA, 2003

Lager A, Webb KJ, Black CJJ, Singleton M, Sorbie KS (2008) Low salinity oil recovery-an experimental investigation. Petrophysics 49(1):28-35 
Laherrere J (2001) Estimates of oil reserves, EMF/IEA/IEW Meeting, IIASA Laxenburg, Austria

Landa-Marbán D, Radu FA, Nordbotten JM (2017) Modeling and simulation of microbial enhanced oil recovery including interfacial area. Transp Porous Media 120(2):395-413

Lashgari HR, Sun A, Zhang T, Pope GA, Lake LW (2019) Evaluation of carbon dioxide storage and miscible gas EOR in shale oil reservoirs. Fuel 241:1223-1235

Li Y-B, Gao H, Pu W-F, Yang L, Dong H, Zhang X, Wu R, Li Q (2017) A novel displacement mechanism of $\mathrm{CO}_{2}$-assisted steam flooding for highly acidic heavy oil reservoir: an experimental study. In: SPE Abu Dhabi international petroleum exhibition $\&$ conference. Society of Petroleum Engineers

Littmann W (1997) Application of surface-active agents in petroleum production. Hand book of surface and colloid chemistry by CRC Press. LLC, pp 689-699

Liu Z, Wang H, Blackbourn G, Ma F, He Z, Wen Z, Wang Z, Yang Z, Luan T, Wu Z (2019) Heavy oils and oil sands: global distribution and resource assessment. Acta Geol Sin 93(1):199-212

Lucía Ó, Domínguez A, Sarnago H, Burdío JM (2018) Induction heating. Control Power Electron Convert Syst Chapter 21(2):265-287

Mai A, Bryan J, Goodarzi N, Kantzas A (2009) Insights into nonthermal recovery of heavy oil. J Can Pet Technol 48(03):27-35

Manrique EJ, Muci VE, Gurfinkel ME (2007) EOR field experiences in carbonate reservoirs in the United States. SPE Reserv Eval Eng 10(06):667-686

Marhaendrajana T, Ridwan MG, Kamil MI, Permadi P (2018) Wettability alteration induced by surface roughening during low salinity waterflooding. J Eng Technol Sci 50(5):635-649

Martin EJ, Mumford KG, Kueper BH, Siemens GA (2017) Gas formation in sand and clay during electrical resistance heating. Int $\mathrm{J}$ Heat Mass Transf 110:855-862

Meribout M (2018) On using ultrasonic-assisted enhanced oil recovery (EOR): recent practical achievements and future prospects. IEEE Access 6:51110-51118

Mohammadian E, Shirazi MA, Idris AK (2011) Enhancing oil recovery through application of ultrasonic assisted waterflooding. In: SPE Asia pacific oil and gas conference and exhibition. Society of Petroleum Engineers

Mohammadian E, Junin R, Rahmani O, Idris AK (2013) Effects of sonication radiation on oil recovery by ultrasonic waves stimulated water-flooding. Ultrasonics 53(2):607-614

Mohsin M, Meribout M (2012) A microwave based simulation study for enhanced oil recovery. In: 2012 Asia-pacific symposium on electromagnetic compatibility (APEMC). IEEE

Mohsin M, Meribout M (2015) An extended model for ultrasonic-based enhanced oil recovery with experimental validation. Ultrason Sonochem 23:413-423

Mozafari M, Nasri Z (2017) Operational conditions effects on Iranian heavy oil upgrading using microwave irradiation. J Pet Sci Eng 151:40-48

Mukhametshina A, Martynova E (2013) Electromagnetic heating of heavy oil and bitumen: a review of experimental studies and field applications. J Pet Eng 2013: Article ID 476519, 7 p

Mullakaev M, Abramov O, Abramov V (2008) Development and study of operating efficiency of technological ultrasonic installations. Chem Pet Eng 44(7-8):433-440

Mullakaev M, Abramov O, Abramov V, Gradov O, Pechkov A (2009a) An ultrasonic technology for productivity restoration in low-flow boreholes. Chem Pet Eng 45(3-4):203-210

Mullakaev M, Abramov VO, Pechkov A (2009b) Ultrasonic unit for restoring oil wells. Chem Pet Eng 45(3-4):133-137

Mullakaev M, Abramov V, Abramova A (2015) Development of ultrasonic equipment and technology for well stimulation and enhanced oil recovery. J Pet Sci Eng 125:201-208
Mullakaev M, Abramov V, Abramova A (2017) Ultrasonic automated oil well complex and technology for enhancing marginal well productivity and heavy oil recovery. J Pet Sci Eng 159:1-7

Mutyala S, Fairbridge C, Paré JJ, Bélanger JM, Ng S, Hawkins R (2010) Microwave applications to oil sands and petroleum: a review. Fuel Process Technol 91(2):127-135

Naderi K, Babadagli T (2008a) Clarifications on oil/heavy oil recovery under ultrasonic radiation through core and $2 \mathrm{D}$ visualization experiments. J Can Pet Technol 47(11):56-62

Naderi K, Babadagli T (2008b) Effect of ultrasonic intensity and frequency on heavy-oil recovery from different wettability rocks. In: International thermal operations and heavy oil symposium. Society of Petroleum Engineers

Naderi K, Babadagli T (2010) Influence of intensity and frequency of ultrasonic waves on capillary interaction and oil recovery from different rock types. Ultrason Sonochem 17(3):500-508

Najafi I (2010) A mathematical analysis of the mechanism of ultrasonic induced fluid percolation in porous media. In: SPE annual technical conference and exhibition

Nasr NH, Mahmood SM, Akbari S, Hematpur H (2020) A comparison of foam stability at varying salinities and surfactant concentrations using bulk foam tests and sandpack flooding. $\mathrm{J}$ Pet Explor Prod Technol 10(2):271-282

Neretin V, Yudin V (1981) Results of experimental study of the influence of acoustic treatment on percolation processes in saturated porous media. Topics in Nonlinear Geophysics (Voprosi nelineinoy geofisiki): All Union Research Institute of Nuclear Geophysics and Geochemistry, pp 132-137

Nguyen DD, Ngo HH, Yoon YS, Chang SW, Bui HH (2016) A new approach involving a multi transducer ultrasonic system for cleaning turbine engines' oil filters under practical conditions. Ultrasonics 71:256-263

Nikolaevskii V (1992) Rock vibration and finite oil recovery. Fluid Dyn 27(5):689-696

Nosov VA (1965) Ultrasonics in the chemical industry. Consultants Bureau

Núñez-López V, Gil-Egui R, Hosseini SA (2019) Environmental and operational performance of $\mathrm{CO}_{2}$-EOR as a CCUS technology: a Cranfield example with dynamic LCA considerations. Energies 12(3):448

Okassa FD, Godi A, De Simoni M, Manotti M, Maddinelli G (2010) A nonconventional EOR technology using RF/MW heating coupled with a new patented well/reservoir interface. In: SPE annual technical conference and exhibition. Society of Petroleum Engineers

Oliveira HJ, Barillas LM, da Mata W, Dutra TV (2009) Energetic optimization to heavy oil recovery by electromagnetic resistive heating (ERH). In: Latin American and Caribbean petroleum engineering conference. Society of Petroleum Engineers

Oloumi D, Rambabu K (2016) Microwave heating of heavy oil reservoirs: a critical analysis. Microw Opt Technol Lett 58(4):809-813

Ovalles C, Fonseca A, Lara A, Alvarado V, Urrecheaga K, Ranson A, Mendoza H (2002) Opportunities of downhole dielectric heating in Venezuela: three case studies involving medium, heavy and extra-heavy crude oil reservoirs. In: SPE international thermal operations and heavy oil symposium and international horizontal well technology conference. Society of Petroleum Engineers

Patel J, Borgohain S, Kumar M, Rangarajan V, Somasundaran P, Sen R (2015) Recent developments in microbial enhanced oil recovery. Renew Sustain Energy Rev 52:1539-1558

Perera MSA, Gamage RP, Rathnaweera TD, Ranathunga AS, Koay A, Choi X (2016) A review of $\mathrm{CO}_{2}$-enhanced oil recovery with a simulated sensitivity analysis. Energies 9(7):481

Pogosyan A, Simkin E, Stremovskiy E, Surguyev M, Shnirel'man A (1989) Separation of hydrocarbon fluid and water in an elastic wave field acting on a porous reservoir medium. Doklady- earth science sections, Silver Spring

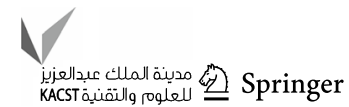


Pollen EN, Berg CF (2018) Experimental investigation of osmosis as a mechanism for low-salinity EOR. In: Abu Dhabi international petroleum exhibition \& conference. Society of Petroleum Engineers, 12-15 November, Abu Dhabi, UAE, pp 1-20

Putra W, Hakiki F (2019) Microbial enhanced oil recovery: interfacial tension and biosurfactant-bacteria growth. J Pet Explor Prod Technol 9(3):2353-2374

Rai SK, Bera A, Mandal A (2015) Modeling of surfactant and surfactant-polymer flooding for enhanced oil recovery using STARS (CMG) software. J Pet Explor Prod Technol 5(1):1-11

Ramcharan T, Hosein R (2019) Radio frequency heating combined with solvent extraction - a method for oil recovery from surface oil sands. J Pet Sci Eng 179:328-336

Rehman MM, Meribout M (2012) Conventional versus electrical enhanced oil recovery: a review. J Pet Explor Prod Technol 2(4):157-167

Sadeghi A, Hassanzadeh H, Harding TG (2017) A comparative study of oil sands preheating using electromagnetic waves, electrical heaters and steam circulation. Int J Heat Mass Transf 111:908-916

Saeedfar A, Law DH-S (2018) Wide frequency range modeling of electromagnetic heating for heavy oil recovery. Schlumberger Technology Corporation, Houston

Saeedfar A, Lawton D, Osadetz K (2016) Directional RF heating for heavy oil recovery using antenna array beam-forming. In: SPE Canada heavy oil technical conference. Society of Petroleum Engineers

Safdel M, Anbaz MA, Daryasafar A, Jamialahmadi M (2017) Microbial enhanced oil recovery: a critical review on worldwide implemented field trials in different countries. Renew Sustain Energy Rev 74:159-172

Sahni A, Kumar M, Knapp RB (2000) Electromagnetic heating methods for heavy oil reservoirs. Lawrence Livermore National Lab, California

Samin AM, Manan MA, Idris AK, Yekeen N, Said M, Alghol A (2017) Protein foam application for enhanced oil recovery. J Dispers Sci Technol 38(4):604-609

Saneifar M, Heidari Z, Linroth M, Purba S (2017) Effect of heterogeneity on fluid-injectivity loss during water-alternating-gas injection in the scurry area canyon reef operators committee unit. SPE Reservoir Eval Eng 20:293-303

Shah DO (2012) Improved oil recovery by surfactant and polymer flooding. Elsevier, Amsterdam

Shaw Resource Services I (1992) Sona-tool test information. Sonic well stimulation research pushed 1970. Shaw Resource Services, Inc., p 40

She H, Kong D, Li Y, Hu Z, Guo H (2019) Recent advance of microbial enhanced oil recovery (MEOR) in China. Geofluids, Article ID 1871392

Shen C (2013) SAGD for heavy oil recovery. Enhanced oil recovery field case studies, chapter 17. Gulf Professional Publishing, Houston, pp 413-445

Sheng JJ (2013) Cyclic steam stimulation. Enhanced oil recovery field case studies, chapter 16. Gulf Professional Publishing, Houston, pp 389-412

Sheng JJ (2014) Critical review of low-salinity waterflooding. J Pet Sci Eng 120:216-224

Sheng JJ (2015) Enhanced oil recovery in shale reservoirs by gas injection. J Natl Gas Sci Eng 22:252-259

Shi C, Yang W, Chen J, Sun X, Chen W, An H, Pei M (2017) Application and mechanism of ultrasonic static mixer in heavy oil viscosity reduction. Ultrason Sonochem 37:648-653

Speight JG (2011) An introduction to petroleum technology, economics, and politics. Wiley, Hoboken

Speight JG (2013) Enhanced recovery methods for heavy oil and tar sands. Elsevier, Amsterdam
Stevens S, Kuuskraa V, O’Donnell J (1999) Enhanced oil recovery scoping study. Final report, EPRI, Palo Alto, CA

Suleimanov BA, Ismayilov FS, Dyshin OA, Veliyev EF (2016) Selection methodology for screening evaluation of EOR methods. Pet Sci Technol 34(10):961-970

Sun R, Liang C, Liu J, Lin L, Xiong Q, Wu S (2011) Effect of ultrasonic treatment on damage relieving of porous media. In: 2011 international conference on electrical and control engineering (ICECE). IEEE

Syed AH, Idris AK, Mohshim DF, Yekeen N, Buriro MA (2019) Influence of lauryl betaine on aqueous solution stability, foamability and foam stability. J Pet Explor Prod Technol 9(4):2659-2665

Taheri-Shakib J, Naderi H, Salimidelshad Y, Teymouri A, Shekarifard A (2018) Using ultrasonic as a new approach for elimination of inorganic scales $(\mathrm{NaCl})$ : an experimental study. J Pet Explor Prod Technol 8(2):553-564

Thomas S (2008) Enhanced oil recovery—an overview. Oil Gas Sci Technol Revue de l'IFP 63(1):9-19

Tovar FD, Barrufet MA, Schechter DS (2018) Gas Injection for EOR in organic rich shale. Part I: operational philosophy. In: SPE improved oil recovery conference. Society of Petroleum Engineers

Troch P, Vandersteene F, Su Z, Hoeben R, Wuethrich M (1996) Estimating microwave observation depth in bare soil through multifrequency scatterometry. In: 1st EMSL user workshop proceedings, Ispra, Italy

Verma MK (2015) Fundamentals of carbon dioxide-enhanced oil recovery $\left(\mathrm{CO}_{2}\right.$-EOR): a supporting document of the assessment methodology for hydrocarbon recovery using $\mathrm{CO}_{2}$-EOR associated with carbon sequestration. Washington, DC: US Department of the Interior, US Geological Survey

Vermeulen F, McGee B (2000) In-situ electromagnetic heating for hydrocarbon recovery and environmental remediation. J Can Pet Technol. https://doi.org/10.2118/00-08-DAS

Viebahn P, Vallentin D, Hoeller S (2015) Integrated assessment of carbon capture and storage (CCS) in South Africa's power sector. Energies 8:14380-14406

Wan T, Yu Y, Sheng JJ (2015) Experimental and numerical study of the EOR potential in liquid-rich shales by cyclic gas injection. $\mathrm{J}$ Unconv Oil Gas Resour 12:56-67

Wan C, Wang R, Zhou W, Li L (2019) Experimental study on viscosity reduction of heavy oil by hydrogen donors using a cavitating jet. RSC Adv 9(5):2509-2515

Wang Z, Zeng J, Song H, Li F (2017) Research on ultrasonic excitation for the removal of drilling fluid plug, paraffin deposition plug, polymer plug and inorganic scale plug for near-well ultrasonic processing technology. Ultrason Sonochem 36:162-167

Wang Z, Gao D, Fang J (2018) Numerical simulation of RF heating heavy oil reservoir based on the coupling between electromagnetic and temperature field. Fuel 220:14-24

Wang Z, Gao D, Diao B, Tan L, Zhang W, Liu K (2019) Comparative performance of electric heater vs. RF heating for heavy oil recovery. Appl Therm Eng 160:114105

Wang Z, Fang R, Guo H (2020) Advances in ultrasonic production units for enhanced oil recovery in China. Ultrason Sonochem 60:104791

Wegener DC, Zornes DR, Maloney DR, Vienot ME, Fraim ML (2001) Heavy oil viscosity reduction and production. Google Patents

Westermark R, Brett J, Maloney D (2001) Enhanced oil recovery with downhole vibration stimulation. In: SPE production and operations symposium. Society of Petroleum Engineers

Williams B (2003) Progress in IOR-technology, economics deemed critical to staving off world's oil production. Oil Gas J 101(30):18-25 
Wu Z, Liu H (2019) Investigation of hot-water flooding after steam injection to improve oil recovery in thin heavy-oil reservoir. $\mathbf{J}$ Pet Explor Prod Technol 9(2):1547-1554

Xiaoxiong LI, Jiang Y, Yongbin WU, Jialu WA (2018) A mathematical model and relevant index prediction for constant-temperature electric heating of dual-horizontal-well SAGD start-up. Pet Explor Dev 45(5):895-902

Xu HX, Pu CS, Zhao SS, Li YH, Shen HN (2011) Experimental study and application of high power ultrasonic treatment for removal of near wellbore paraffin precipitation damage. J Southwest Petrol Univ Sci Technol Edn 33(5):146-151

Yao ZX, Li JX, Wang K, Song YN, Li X (2019) Experimental and numerical study on direct electrical heating for plug removal of subsea waxy crude pipelines. Int J Heat Mass Transf 143:118489

Yernazarova A, Kayirmanova G, Baubekova A, Zhubanova A (2016) Microbial enhanced oil recovery. In: Chemical enhanced oil recovery (cEOR) - a practical overview (p 200). InTech

Yongbin W, Xingmin L, Wanjun H, Fang Z, Yueyue F, Weinan A, Xiaoxiong L (2017) Numerical simulation of electrical-heating assisted SAGD in heterogeneous heavy oil reservoirs. In: SPE reservoir characterisation and simulation conference and exhibition. Society of Petroleum Engineers

Yu M, Zeinijahromi A, Bedrikovetsky P, Genolet L, Behr A, Kowollik P, Hussain F (2019) Effects of fines migration on oil displacement by low-salinity water. J Pet Sci Eng 175:665-680

Zahid S, Khan HA (2007) A review on microbial EOR with special reference to its use in marginal and/or mature assets. In: International oil conference and exhibition in Mexico. Society of Petroleum Engineers, pp. 1-9, Veracruz, Mexico
Zekri AY, Harahap BA, Al-Attar HH, Lwisa EG (2019) Effectiveness of oil displacement by sequential low-salinity waterflooding in low-permeability fractured and non-fractured chalky limestone cores. J Pet Explor Prod Technol 9(1):271-280

Zhang P, Tweheyo MT, Austad T (2007) Wettability alteration and improved oil recovery by spontaneous imbibition of seawater into chalk: impact of the potential determining ions $\mathrm{Ca}_{2+}, \mathrm{Mg}_{2+}$, and $\mathrm{SO}_{4}{ }^{2-}$. Colloids Surf A 301(1-3):199-208

Zhang X, Chen X, Ma L, Zhou Y, Shi Y, Yang G (2013) Research and application of ultrasonic oil production technique. Ground Water $1-25$

Zhang Y, Adam M, Hart A, Wood J, Rigby SP, Robinson JP (2018) Impact of oil composition on microwave heating behavior of heavy oils. Energy Fuels 32(2):1592-1599

Zhao R, Chen Y, Huan R, Castanier LM, Kovscek AR (2015) An experimental investigation of the in situ combustion behavior of Karamay crude oil. J Pet Sci Eng 127:82-92

Zhu T, Huang X, Vajjha PK (2005) Downhole harmonic vibration oildisplacement system: a new IOR tool. SPE Western Regional Meeting, Society of Petroleum Engineers

Publisher's Note Springer Nature remains neutral with regard to jurisdictional claims in published maps and institutional affiliations. 